\title{
Underground explosions: estimating the safe distance
}

1 Jörg Zimbelmann Dr.-Ing.

Project Manager, Boley Geotechnik Consulting Engineers, Munich, Germany (corresponding author: j.zimbelmann@boleygeotechnik.de)
2 Conrad Boley Univ.-Prof. Dr.-Ing.

Director, Department for Soil Mechanics and Soil Engineering, Faculty for Civil Engineering, University of the German Armed Forces, Munich, Germany; Chief Executive Officer, Boley Geotechnik Consulting Engineers, Munich, Germany

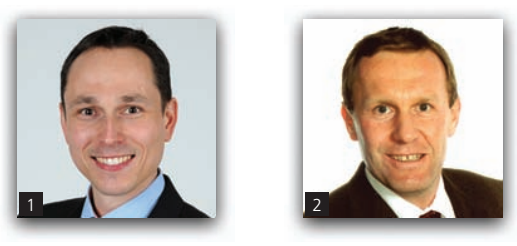

Underground explosions may contain an even more devastating potential than comparable free explosions in air, because they can produce significantly greater pressures and stronger momenta and the explosive waves may decay more slowly with increasing distance. For civil applications such as clearance of explosive ordnance, explosive tunnelling and surface mining in the vicinity of buildings, a tool is desirable, with which the safe distance $r_{\text {hor,safer }}$ beyond which a building remains undamaged, may be evaluated in a fast and simple manner. The procedure to derive such a tool is exemplarily demonstrated for near-surface, underground explosions with a charge mass of $125 \mathrm{~kg}$ of trinitrotoluene, dry sand as foundation soil and a building with shallow foundation and no basement. Numerical simulations were carried out with the commercial hydrocode Autodyn. To track the explosion-induced wave up to sufficiently large distances, the modelling strategy called the 'moving window' was developed. With respect to the damage patterns, 'air blast', 'foundation-induced excitation of the structure to vibrations' and 'inadmissible inclination of foundations due to subsidence', the numerical time courses of the relevant wave parameters were evaluated. The result is one chart for the safe distance as a function of the explosive's charge depth.

\section{Notation}

c wave speed: $\mathrm{m} / \mathrm{s}$

$c_{0} \quad$ parameter of a $v_{\mathrm{S}}-v_{1}$ relation: $\mathrm{m} / \mathrm{s}$

$c_{\mathrm{BU}}$ bulk sound speed for unloading: $\mathrm{m} / \mathrm{s}$

$c_{\mathrm{B}} \quad$ bulk sound speed: $\mathrm{m} / \mathrm{s}$

$c_{\mathrm{el}} \quad$ elastic wave speed: $\mathrm{m} / \mathrm{s}$

$c_{\mathrm{pl}} \quad$ plastic wave speed: $\mathrm{m} / \mathrm{s}$

$d_{\mathrm{TNT}} \quad$ charge depth: $\mathrm{m}$

E Young's modulus: N/mm ${ }^{2}$

$E_{\mathrm{S}} \quad$ odometric modulus: $\mathrm{N} / \mathrm{mm}^{2}$

$e \quad$ specific internal energy: $\mathrm{J} / \mathrm{kg}$

$f$ frequency: $\mathrm{Hz}$

$f_{i} \quad$ nodal forces

G shear modulus: $\mathrm{N} / \mathrm{mm}^{2}$

$I_{\mathrm{P}} \quad$ index of plasticity

$K \quad$ bulk modulus: $\mathrm{N} / \mathrm{mm}^{2}$

$p$ pressure: $\mathrm{N} / \mathrm{mm}^{2}$

$p_{\text {shift }} \quad$ pressure offset: $\mathrm{N} / \mathrm{mm}^{2}$

$r_{\text {hor }} \quad$ horizontal distance from the explosion's epicentre: $m$

$S_{1} \quad$ parameter of a $v_{\mathrm{S}}-v_{1}$ relation

$S_{i j} \quad$ deviatoric stress tensor

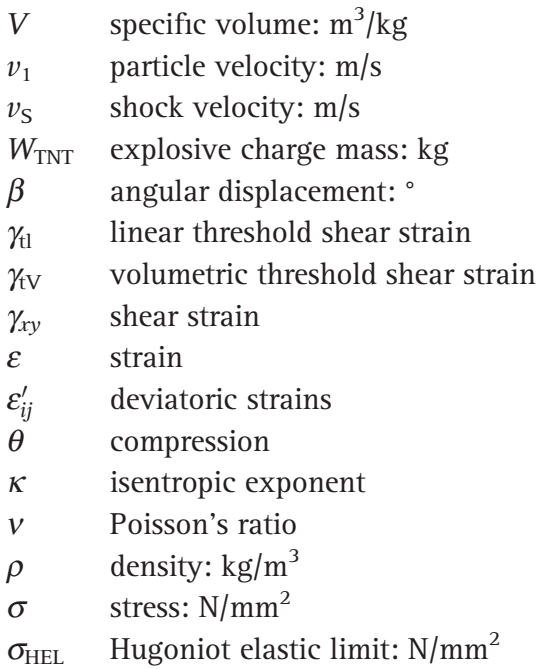

\section{Introduction}

Explosions are characterised by an abrupt expansion of the gaseous reaction products by means of a shock wave with very high pressures and extreme strain rates. If compared with free 
explosions in air and depending on the determining factors such as explosive charge weight, charge depth and on-site soil conditions, explosions below the soil surface may produce significantly greater pressures and longer exposure times (i.e. stronger momenta), and the pressures and particle movements may decay more slowly with increasing distance (Drake and Little, 1983; Laine, 2012).

Explosions and their effects on buildings are simulated by means of hydrocodes. These explicit solvers are used to simulate unsteady, dynamic problems by simultaneously solving the conservation equations of mass, momentum and energy while taking into account the initial and boundary conditions (Grujicic et al., 2006). Examples of such simulations in the relevant literature are

- the construction of underground shelters designed to resist underground explosions in soil and rock (Bessette, 2008; Laine, 2001; Lu et al., 2005; Wang et al., 2005)

- the scenario of a terrorist attack with a contact explosion at ground level or an explosion slightly above the ground level (Lu and Wang, 2006; Wu and Hao, 2005, 2007).

Hydrocode simulations are usually very time-consuming and require a certain level of expertise in the field of short-time dynamics. In civil applications such as clearing of ordnance, tunnel blasting and surface mining, buildings are usually located in the vicinity of the underground explosion. Therefore, a tool for evaluating the safe distance $r_{\text {hor,safe, beyond which an }}$ underground explosion (characterised by the type of explosive, the charge weight and the charge depth) is likely to cause no structural damage to a building, is desirable.

This paper introduces a way to generate such a decision aid. The tool consists of a diagram with which the safe distance $r_{\text {horsafe }}$ for undamaged buildings may be identified in a fast and simple manner. The procedure is demonstrated for shallow, underground explosions with a charge mass of $125 \mathrm{~kg}$ of trinitrotoluene (TNT),

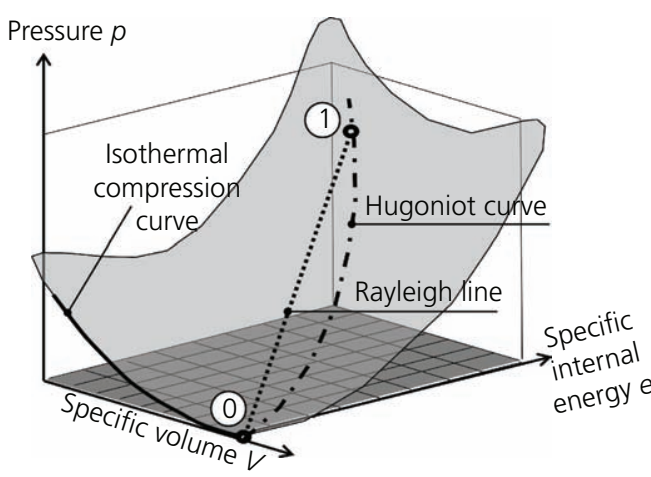

Figure 1. State surface, Rayleigh line and Hugoniot curve; according to Hiermaier (2008) the underground consisting of dry sand and shallow-founded buildings without a basement.

The whole article is based on the thesis by Zimbelmann (2015).

\section{Theoretical basics of shock waves}

\section{Equation of state and simplified one-dimensional approach}

Explosion-induced waves are shock waves, at least in the vicinity of the explosive, where geometric and material damping is of minor influence. Shock waves are always compression waves. They are characterised by extremely high pressures and a very steep wave front. Thus, on the passage of the shock front, the particle velocity $v$ and the state variables pressure $p$, density $\rho$ (or specific volume $V=1 / \rho$ ) and specific internal energy $e$ change abruptly - the material jumps from the preshock state to the shocked state almost instantaneously. However, the balance equations for mass, momentum and energy must always be met. Thus, shock deformation is a thermodynamic process, and a correct description of the material's behaviour must therefore incorporate the specific internal energy $e$. In general, this is done by means of an equation of state (EOS) $p=(\rho, e)$ expressing isotropic pressure $p$ as a function of density $\rho$ and specific internal energy $e$. The state surface given by the EOS defines the locus of any state of thermodynamic equilibrium (Figure 1). The abrupt change of state during transition of a shock wave is described by the Rayleigh line. This non-equilibrium path outside the state surface connects the initial state $\left(p_{0}, V_{0}, e_{0}\right)$ and the shock state $\left(p_{1}, V_{1}, e_{1}\right)$. The Hugoniot curve describes all shock states that may be reached from the initial state.

In a simplified one-dimensional (1D) model, a fluid without any shear strength is assumed to be overrun by a discontinuity (the shock front). The latter propagates with the shock speed $v_{\mathrm{S}}$ and separates the unshocked material in the initial state ' 0 ' from the shocked material with state ' 1 ' (Figure 2). For a volume initially at rest $\left(v_{0}=0\right)$, the conservation of mass, momentum and energy may be written in the form of Equations 1 to 3. These are the Rankine-Hugoniot equations. A detailed derivation may be looked up in the books by Meyers (1994) and Hiermaier (2008). Dexterous rearrangement of Equations 1 and 2 and insertion in

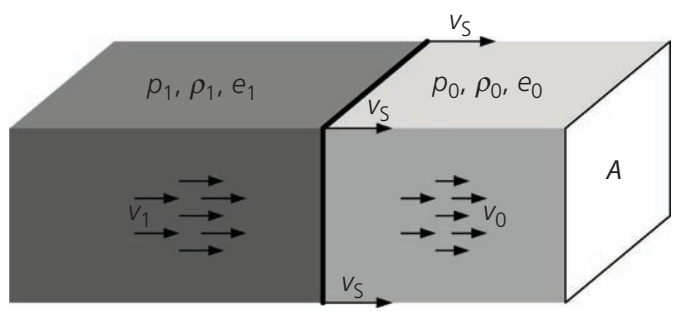

Figure 2. Riemann problem - planar shock wave in a fluid (uniaxial state of strain) 
Underground explosions: estimating the

safe distance

Zimbelmann and Boley
Equation 3 lead to the Hugoniot curve (Equation 4), which is a formulation of the conservation of energy that depends solely on thermodynamic quantities.

1. $\rho_{0} v_{\mathrm{S}}=\rho_{1}\left(v_{\mathrm{S}}-v_{1}\right)$

2. $p_{1}-p_{0}=\rho_{0} v_{\mathrm{S}} v_{1}$

3. $p_{1} v_{1}=\frac{1}{2} \rho_{0} v_{\mathrm{S}} v_{1}^{2}+\rho_{0} v_{\mathrm{S}}\left(e_{1}-e_{0}\right)$

$$
\begin{aligned}
e_{1}-e_{0} & =\frac{1}{2}\left(p_{1}+p_{0}\right)\left(\frac{1}{\rho_{0}}-\frac{1}{\rho_{1}}\right) \\
& =\frac{1}{2}\left(p_{1}+p_{0}\right)\left(V_{0}-V_{1}\right)
\end{aligned}
$$$$
4 .
$$

As there are only three Rankine-Hugoniot equations for five variables $\left(v_{\mathrm{S}}, p_{1}, v_{1}, \rho_{1}\right.$ and $\left.e_{1}\right)$, an additional equation is needed. In general, this is an EOS. In the $1 \mathrm{D}$ case, a $v_{\mathrm{S}}-v_{1}$ relation (Equation 5), which has to be experimentally determined, is sufficient. Although it is often called the simplest form of an EOS, a $v_{\mathrm{S}}-v_{1}$ relation only describes the Hugoniot curve. For the generation of an EOS, further assumptions need to be made.

5. $v_{\mathrm{S}}=c_{0}+\sum_{i=1}^{n} S_{i} v_{1}^{i}$

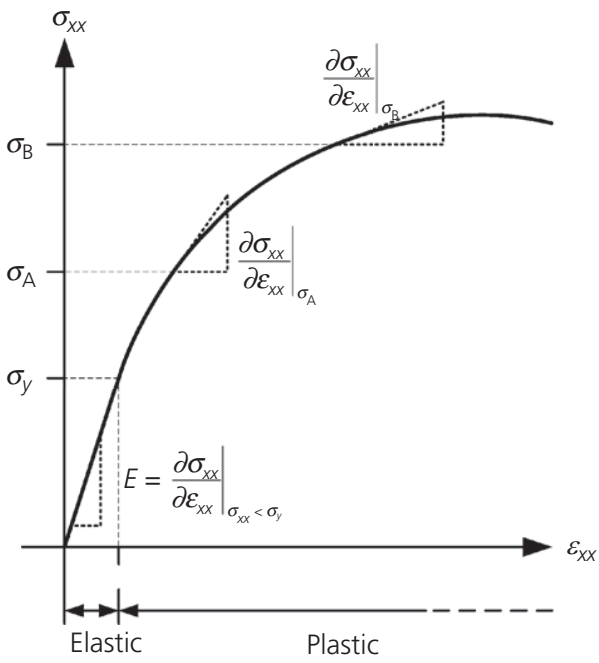

(a)

\section{Preconditions for the formation of shock waves and} hydrodynamic behaviour

From elasticity theory, it is known that in space, compression waves propagate with the elastic wave speed $c_{\mathrm{el}, \mathrm{P}}$ (Equation 6). In a uniaxial state of stress - as is the case for a bar with a constant cross-section - the compression wave advances with a wave speed $c_{\mathrm{el}, \mathrm{L}}$ according to Equation 7.

$$
\begin{aligned}
c_{\mathrm{el}, \mathrm{P}} & =\sqrt{\frac{1-v}{(1+v)(1-2 v)} \frac{E}{\rho}}=\sqrt{\frac{K+(4 / 3) G}{\rho}} \\
& =\sqrt{\frac{E_{\mathrm{S}}}{\rho}}
\end{aligned}
$$

7. $c_{\mathrm{el}, \mathrm{L}}=\sqrt{\frac{E}{\rho}}=\sqrt{\frac{(1+v)(1-2 v)}{1-v}} c_{\mathrm{el}, \mathrm{P}}$

For a uniaxial state of stress as in a bar and axial stresses $\sigma_{x x}$ above the yield stress $\sigma_{\mathrm{Y}}$, Equation 7 is no longer valid, as the stress-strain curve's slope $\partial \sigma_{x x} / \partial \varepsilon_{x x}$ is less than Young's modulus. As $\partial \sigma_{x x} / \partial \varepsilon_{x x}$ steadily decreases with increasing $\sigma_{x x}$ (Figure 3(a)), plastic wavelets triggered at stresses above the yield point $\sigma_{\mathrm{Y}}$ propagate with a plastic wave speed $c_{\mathrm{pl}, \mathrm{L}}$, which is smaller than the elastic wave speed $c_{\mathrm{el}, \mathrm{L}}$ of a bar. Since the elastic wavelets outrun the plastic wavelets, the initial wave is split into an elastic precursor and a trailing plastic wave (Figure 3(b)).

For the same material in a uniaxial state of strain, the plastic part of the compression curve is convex. Due to this convexity, the

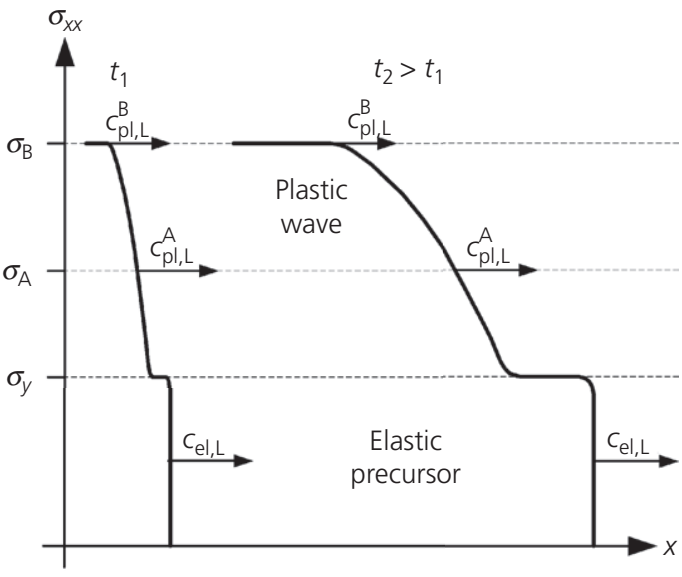

(b)

Figure 3. Uniaxial state of stress in a bar: (a) stress-strain curve and (b) evolution of the wave front at different instants of time, according to Meyers (1994) 
Underground explosions: estimating the

safe distance

Zimbelmann and Boley tangent bulk modulus $K$ (Equation 8) and therefore the wave speed continuously increase with stress. Hence, plastic wavelets triggered at higher stresses catch up with plastic wavelets initiated at lower stresses. Superposition of these plastic wavelets causes a steepening of the wave front and the formation of a shock wave (Figure 4(b)). At stresses above the imaginary intersection of the elastic and the plastic compression curve (point $\mathrm{B}$ in the upper part of Figure 4(a)), even the elastic precursor is outrun. Besides the convexity of the compression curve, a sufficiently rapid loading is imperative for the formation of a shock wave. Otherwise, the slower wavelets have already been damped before they can be outrun by faster wavelets.

8. $K=\frac{\partial p}{\partial \theta}=-V \frac{\partial p}{\partial V}=\rho \frac{\partial p}{\partial \rho}$

The maximum principal stress in a uniaxial state of strain, when reaching the yield point, is called the Hugoniot elastic limit $\sigma_{\mathrm{HEL}}$. Assuming elastic perfectly plastic material behaviour and the von Mises yield criterion $\sigma_{1}-\sigma_{3}=\sigma_{\mathrm{Y}}$, the maximum principal stress may be calculated according to Equation 9 (see, for example, Zukas (2004)). With respect to the hydrostatic compression curve $p=f(\theta)$, the $\sigma_{1}$ curve is therefore shifted upwards by a magnitude of $(2 / 3) \sigma_{\mathrm{Y}}$ (the lower part of Figure 4(a)). In the case of $\sigma_{1} \gg$ $\sigma_{\mathrm{HEL}}$, the difference between the $\sigma_{x}\left(\varepsilon_{x}\right)$ and the $p(\theta)$ compression curve vanishes (the upper part of Figure 4(a)). The influence of shear modulus $G$ becomes negligible, and the solid behaves like a fluid. Thus, Equation 6 turns into Equation 10; that is to say, the compression wave propagates with the bulk sound speed $c_{\mathrm{B}}$.

$$
\begin{aligned}
\sigma_{1} & =\frac{E}{3(1-2 v)} \varepsilon_{1}+\frac{2}{3} \sigma_{\mathrm{Y}}=K \varepsilon_{1}+\frac{2}{3} \sigma_{\mathrm{Y}} \\
\text { 9. } \quad & =\sigma_{\mathrm{m}}+\frac{2}{3} \sigma_{\mathrm{Y}}
\end{aligned}
$$

10. $c_{\mathrm{B}}^{2}=\frac{K}{\rho}=\frac{\partial p}{\partial \rho}=-V^{2} \frac{\partial p}{\partial V}$

Due to this hydrodynamic behaviour at high pressures, it is useful and common practice to formulate the compressive behaviour and the shear behaviour with separate constitutive equations according to the decomposition of the stress tensor (Equation 11). The compressive behaviour is therefore described by an $\operatorname{EOS} p(\rho, e)$. A strength model is used to connect deviatoric stresses $S_{i j}$ and deviatoric strains $\varepsilon_{i j}^{\prime}$.
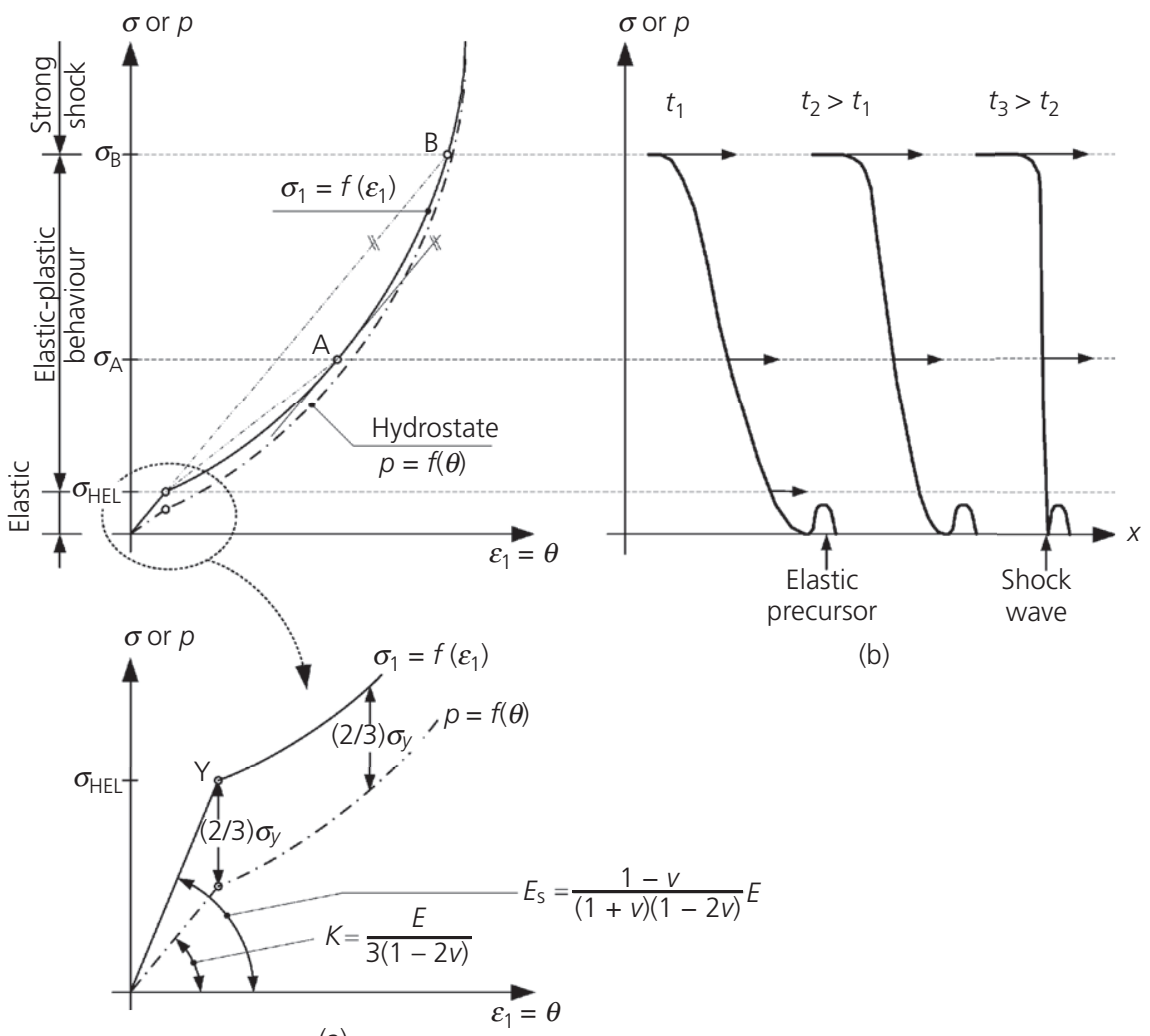

(b)

(a)

Figure 4. Uniaxial state of strain: (a) idealised compression curves,

(b) evolution of the wave front at different instants of time 
Underground explosions: estimating the

safe distance

Zimbelmann and Boley
11. $\sigma_{i j}=\frac{1}{3} I_{1} \delta_{i j}+S_{i j}=-p \delta_{i j}+S_{i j}$

\section{Ground shock}

\section{Basic information}

Explosions generally lead to extremely high pressures. Additionally, explosive waves are very fast, thus leading to a rapid loading and, subsequently (at least for a short period of time), a uniaxial state of strain. Despite phenomena such as crushing and rearrangement of particles, the compression curve for a uniaxial state of strain on the whole is convex for nearly all kinds of soil. Thus, explosions in soil do fulfil all necessary preconditions for the formation of shock waves. Therefore, explosions in soil and the related phenomena are called ground shock.

The maximum pressure $p_{1, \max }$ transmitted into the ground depends on the impedance ratio of the explosive's gaseous reaction products and the surrounding soil. In general, the pressure $p(t)$ and the specific impulse $I$ are used to characterise the explosive loading. Both parameters mainly depend on the following factors (Laine, 2012; Streitkräfteamt Abt V Infrastruktur, 2007)

a type and form of the explosive

n soil properties - for example type of soil, density, void ratio, saturation and grain-size distribution (Omidvar et al., 2012)
- charge depth $d_{\mathrm{TNT}}$

- (horizontal) distance $r_{\text {hor }}$ between the centre of explosion and the observer

- charge weight $W_{\mathrm{TNT}}$.

The charge depth $d_{\mathrm{TNT}}$ largely determines the allocation of the released energy of explosion in the ground and the air. The greater the charge depth, the more explosive energy is transmitted into the ground and the greater the direct ground shock. For sufficiently small depths of burial, the overlying soil is thrown out, and the released energy propagates by way of an air shock wave. Due to the interaction of the air shock wave with the ground surface, an indirect ground shock wave is generated. In comparison to a free explosion in air of the same charge weight, the duration of the pressure phase increases with increasing charge depth, as time is needed for the formation of a cavern. Thus, the charge depth also affects the frequency content. In this regard, the charge weight is of great importance as well. The greater the charge weight, the more low frequencies are stimulated (Heinze, 1987).

\section{Damage patterns due to underground explosions}

Figure 5 shows five principle scenarios for structural damage caused by shallow underground explosions

- flying debris of dispersed soil material

- cratering and soil rupture

- air blast and forced vibrations

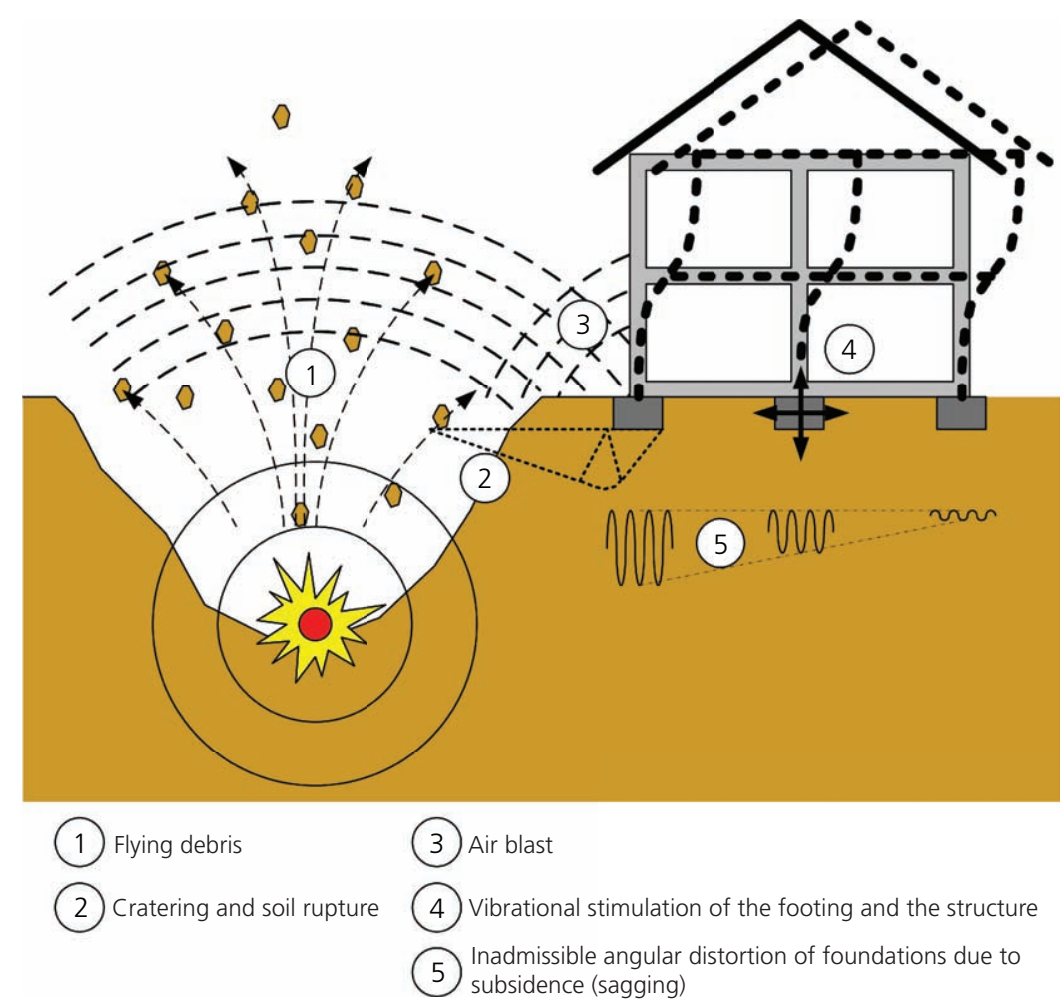

Figure 5. Damage patterns due to underground explosions 
foundation-induced excitation of the structure to vibrations

- inadmissible inclination of foundations due to subsidence.

To date, no publications are known from the relevant literature that consider impairment of overground buildings initiated by underground explosions. Hereafter the damage scenario 'flying debris of dispersed soil material' as well as the near-field failure mode 'cratering and overlapping with the area of influence for soil rupture' will not be considered any further.

\section{Approach for the generation of a decision aid}

Evaluation of the ground shock and air blast parameters as well as their effects on a structure such as deformations, state of stress and degradation is not a trivial problem. By means of empirical models, the ground shock parameters may only be determined approximately. The influence of the explosive's type and form as well as the effects of different soils and their parameters, the interaction of the explosive wave with the ground surface and a possible air shock wave may be captured in much more realistic manner with numerical simulations.

The decision aid was intended to be valid for a large variety of buildings with different sizes, shapes, structures and stiffnesses. Therefore, the interactions of the air and ground shock waves with the structure according to the regarded damage patterns had to be considered separately. Thus, a decoupled analysis was done according to the following procedure (Figure 6). The explosion, the interaction between the explosive's gaseous reaction products and the surrounding soil, and the spreading of the shock wave and its interaction with the soil surface were taken into account by means of numerical simulations. From these, the time courses of relevant wave parameters according to the considered damage patterns - air pressure $p_{1}$, horizontal particle velocity $v_{1}$ and shear strain $\gamma_{x y}$ in the soil - were recorded. These free-field solutions were further processed as shown in the last section of this article. In the last step, the interactions of the air and ground shock waves with the structure were encompassed by comparing the processed, numerical results with empirical, permissible values. It has to be mentioned that decoupled analyses are always accompanied by a loss of information at each interface. However, time expenses for numerical simulations could be significantly reduced as the radial symmetry of the free-field simulation could be taken into account.

\section{Numerical simulations with Autodyn}

In the work presented in this paper, numerical simulations were done using the commercial hydrocode Autodyn, version R15. To allow for large deformations, in particular for the explosive's gaseous reaction products and the surrounding soil, and to capture the blowout of the explosive and further expansion of the air shock wave, all simulations were done using the multimaterial Euler processor.

\section{Autodyn: a short description}

Autodyn is a commercial hydrocode that uses finite-element, finite-difference and finite-volume techniques to solve highly time-dependent problems with geometric non-linearities such as large strains and deformations as well as with material nonlinearities (plasticity, failure etc.). The expression hydrocode is entailed historically due to the earlier mentioned hydrodynamic behaviour under extreme pressures. Various numerical processors have been implemented, such as the Lagrange solver for solid continua and different types of Euler processors for modelling fluids, gases and large distortion, as well as arbitrary Lagrange-Euler, smooth particle hydrodynamics (a mesh-free method) and shell processors. The solution for all these solvers is based on explicit time integration.

As stated earlier, the balance equations for mass, momentum and energy must always be met. While Equations 1-3 represent the conservation of mass, momentum and energy for a gas and the 1D case, the partial differential Equations 12-14 are the conservation equations for the general case. In Autodyn, the partial differential equations are replaced by finite-difference equations. Then the whole problem that needs to be solved consists of the

\begin{tabular}{|l|l|}
\hline \multicolumn{1}{|c|}{$\begin{array}{c}\text { Numerical simulations } \\
\text { (hydrocode) }\end{array}$} & \multicolumn{1}{c}{$\begin{array}{c}\text { Time courses } \\
\text { (free-field solution) }\end{array}$} \\
\hline - $\begin{array}{l}\text { Interaction 'explosive-soil' } \\
\text { - } \begin{array}{l}\text { Wave propagation } \\
\text { Interaction 'wave-soil surface' }\end{array}\end{array} \mid \begin{array}{ll}\text { Air pressure } p_{1} \\
\text { - Horizontal particle velocity } v_{1} \\
\text { Shear strain } \gamma_{x y}\end{array}$ \\
\hline
\end{tabular}

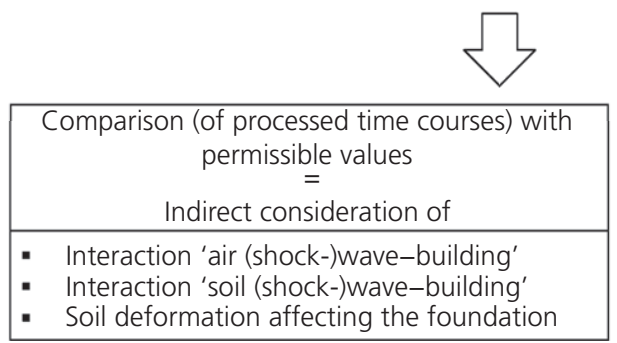

Figure 6. Approach for the generation of a decision aid 


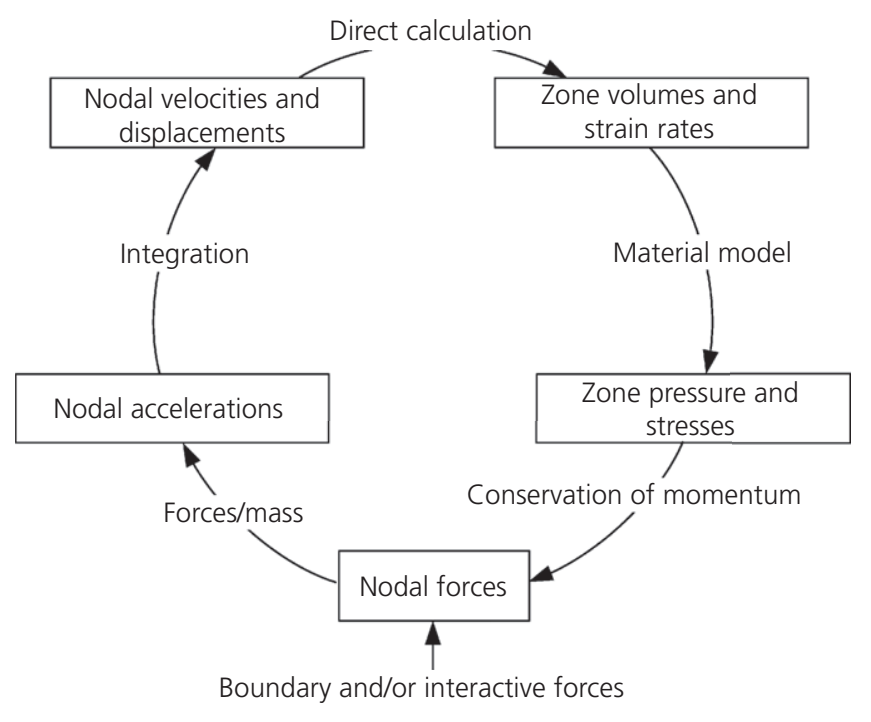

Figure 7. Lagrange computation cycle; according to Century Dynamics Inc. (2005a)

conservation equations together with a material model and a set of initial and boundary conditions. Figure 7 shows the series of calculations that are carried out in every time step for a Lagrange discretisation. First, the boundary and/or interactive forces are updated and combined with the forces for inner zones that were calculated in the previous time step. By using the momentum equation in Equation 15, the nodal accelerations may be computed. Further integration leads to the nodal velocities and displacements. In Lagrange models the mesh moves and deforms with the material. Thus the new volumes and strain rates can be directly computed from the new velocities and displacements. Additionally, the conservation of mass is automatically satisfied and the new density can be calculated using Equation 16. By using the material model in combination with the conservation of energy, the new pressures, stresses and energies may be computed. Conservation of momentum finally gives the new nodal forces $f_{i}$ that are used in the next time step.

In the Euler processor, the governing conservation equations are solved by using a control volume method. The finite-difference equations are solved in two steps: in the first step, the Lagrange discretisation is used, and the mesh moves and deforms. In the second step, the updated variables from the Lagrange solution are mapped back onto the spatially fixed grid of the Euler discretisation.

While the Lagrange solver uses a central difference method which is second-order accurate, the first-order upwind differencing scheme is implemented for the Euler processor.

12. $\frac{\mathrm{d} \rho}{\mathrm{d} t}+\rho \frac{\partial v_{i}}{\partial x_{i}}=0$
13. $\frac{\mathrm{d} v_{i}}{\mathrm{~d} t}=\frac{1}{\rho} \frac{\partial \sigma_{i j}}{\partial x_{j}}+f_{i}$

14. $\frac{\mathrm{d} e}{\mathrm{~d} t}=-\frac{p}{\rho} \frac{\partial v_{i}}{\partial x_{i}}+\frac{1}{\rho} S_{i j} \dot{\varepsilon}_{i j}$

15. $a_{i}=\frac{f_{i}}{m}$

16. $\rho=\frac{\rho_{0} V_{0}}{V}$

The preceding paragraph is based on the AUTODYN Theory Manual (Century Dynamics Inc., 2005a) and the ANSYS Mechanical User's Guide (Ansys Inc., 2013). Further information concerning the implemented routines may be looked up in these references. The relevant portions of these manuals are also summarised in the documents by Fišerová (2006) and Showichen (2008), which are available for free. Anderson (1987), Zukas (2004) and Wilkins (1999) give an introduction to the general theory of hydrocodes.

\section{Material models}

Air was described as an ideal gas. In Autodyn, the associated EOS is implemented in the form of Equation 17. For the simulation, the default values $\rho_{0}=1.225 \times 10^{-3} \mathrm{~g} / \mathrm{cm}^{3}, T=$ $288 \cdot 15 \mathrm{~K}\left(=15^{\circ} \mathrm{C}\right)$ and $p_{0}=101.325 \mathrm{kPa}$ were used. An isentropic exponent $\kappa=1.4$ consequently results in the specific internal energy $e_{0}=206785.7 \mathrm{~J} / \mathrm{kg}$. Since the air pressure is the only relevant parameter, the pressure offset was set to $p_{\text {shift }}=p_{0}=$ $101 \cdot 325 \mathrm{kPa}$. Thus, no unwanted velocities at the soil surface were generated and only the overpressure was recorded.

17. $p_{1}=(\kappa-1) \rho_{1} e_{1}+p_{\text {shift }}$

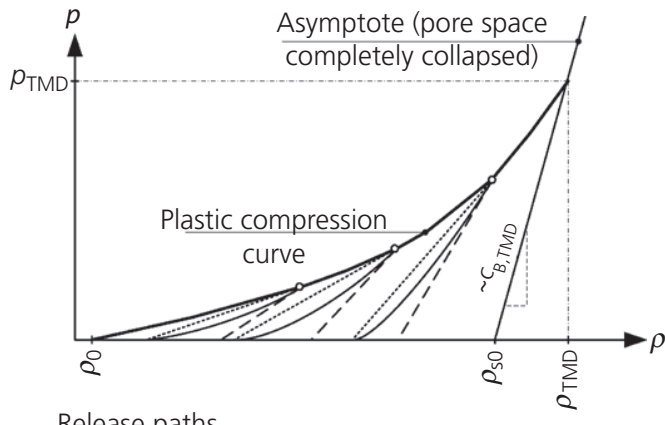

Release paths

_ Curved (reality)

- - - Linear ( $\mathrm{C}_{\mathrm{BU}}$ at onset of unloading = original Sand model)

......... Linear (averaged over entire unloading path = modified model)

Figure 8. Compaction EOS linear in Autodyn and comparison of the unloading paths 
Geotechnical Research

Volume 3 Issue 3
Underground explosions: estimating the

safe distance

Zimbelmann and Boley
TNT was the explosive of choice. As it is a standard explosive and conversion tables exist (at least for the parameters of free explosions in air), the decision aid might be converted to other types of explosive. Simulations were done using the JWL EOS by Jones, Wilkins and Lee (Equation 18), which is a standard EOS for high explosives and is widely used. The constants $A, B, R_{1}, R_{2}$ and $\omega$ need to be determined experimentally depending on the type of explosive. Alternatively, these constants may as well be chosen from tables. For large volumetric strains of the explosive's gaseous reaction products, the first and second terms in Equation 18 become negligible and the JWL EOS approaches the ideal gas equation. For volumetric strains $\varepsilon_{\mathrm{V}}=\left(V-V_{0}\right) / V_{0}>10$ - with $V_{0}$ being the initial volume of the unreacted explosive - the EOS is to be changed from JWL to the ideal gas equation by using Equation 19 for the conversion of the parameter $\omega$ to the isentropic exponent $\kappa$ (Century Dynamics Inc., 2005b). While for Autodyn versions R14 and earlier this change in the EOS had to be done manually, in version R15 it is an automatic process.

$$
\begin{aligned}
p= & A\left(1-\frac{\omega \rho}{R_{1}}\right) \exp \left(-\frac{R_{1}}{\rho}\right) \\
& +B\left(1-\frac{\omega \rho}{R_{2}}\right) \exp \left(-\frac{R_{2}}{\rho}\right)+\omega \rho e
\end{aligned}
$$

19. $\kappa=\omega+1$

The Sand model (Laine and Sandvik, 2001) implemented in the Autodyn material library was used. It is valid for dry sand with loose to medium-dense degree of density. The Sand model includes Compaction EOS linear, the Mo Granular strength model and a failure model. Compaction EOS linear was originally developed for granular materials and therefore is the appropriate choice when modelling non-cohesive soils, as it accounts for plastic compression with different loading and unloading paths (Figure 8). This is the crucial property of granular media that affects damping. Compression is described by a plastic compaction curve $p(\rho)$ and a solid asymptote for the fully compacted material with densities greater than the theoretical maximum density $\rho_{\mathrm{TMD}}$ (Figure 9). Elastic unloading and reloading is described by the density-dependent bulk sound speed $c_{\mathrm{BU}}=f(\lambda)$. Yet here the parameter $\lambda$ describes the density of the completely relieved material at zero pressure. For the work presented in this paper, the $c_{\mathrm{BU}}(\lambda)$ curve was modified based on the data set published in annex ZA of the work by Laine (2012). Figure 10 shows the bulk sound speeds $c_{\mathrm{BU}, \mathrm{SAND}}(\lambda)$ according to the original definition and the $c_{\mathrm{BU}, \mathrm{MOD}}(\lambda)$ curve. The difference between the two definitions is depicted qualitatively in Figure 8: while the original definition $c_{\mathrm{BU}, \mathrm{SAND}}(\lambda)$ was the bulk sound speed at the onset of unloading according to the respective tangent moduli of the plastic compression curve, the modified definition $c_{\mathrm{BU}, \mathrm{MOD}}(\lambda)$ gives unloading paths that are linearly averaged over the real curved unloading paths.

Like Compaction EOS linear, the Mo Granular strength model was developed for granular materials such as powders, soil and sand. It is a modified Drucker-Prager model with a volume independent flow rule of the Prandtl-Reuss type. The yield surface is both pressure- and density-dependent (Equation 20). However, only the pressure-dependent part was used with the definition of the yield surface according to the original Sand model (Figure 11). Although Laine and Sandvik (2001) stated that the shear modulus for elastic unloading and reloading $G_{U}$ had been derived from the measured values of the shear wave velocities, it seemed to be calculated by Equation 21 using the bulk sound speed for unloading $c_{\mathrm{BU}}$ and a constant Poisson's ratio of $v=0 \cdot 23$, which is an appropriate choice for sands. To be

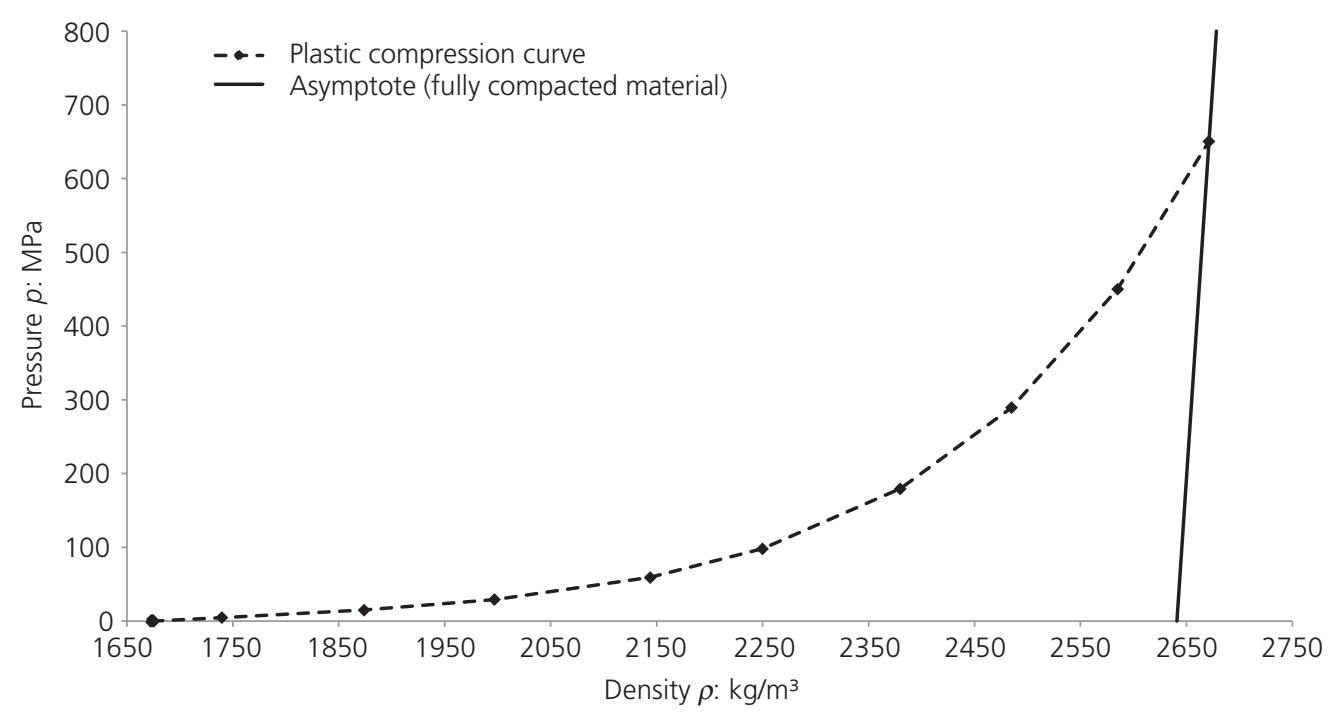

Figure 9. Plastic compaction curve $p(\rho)$ and solid asymptote 


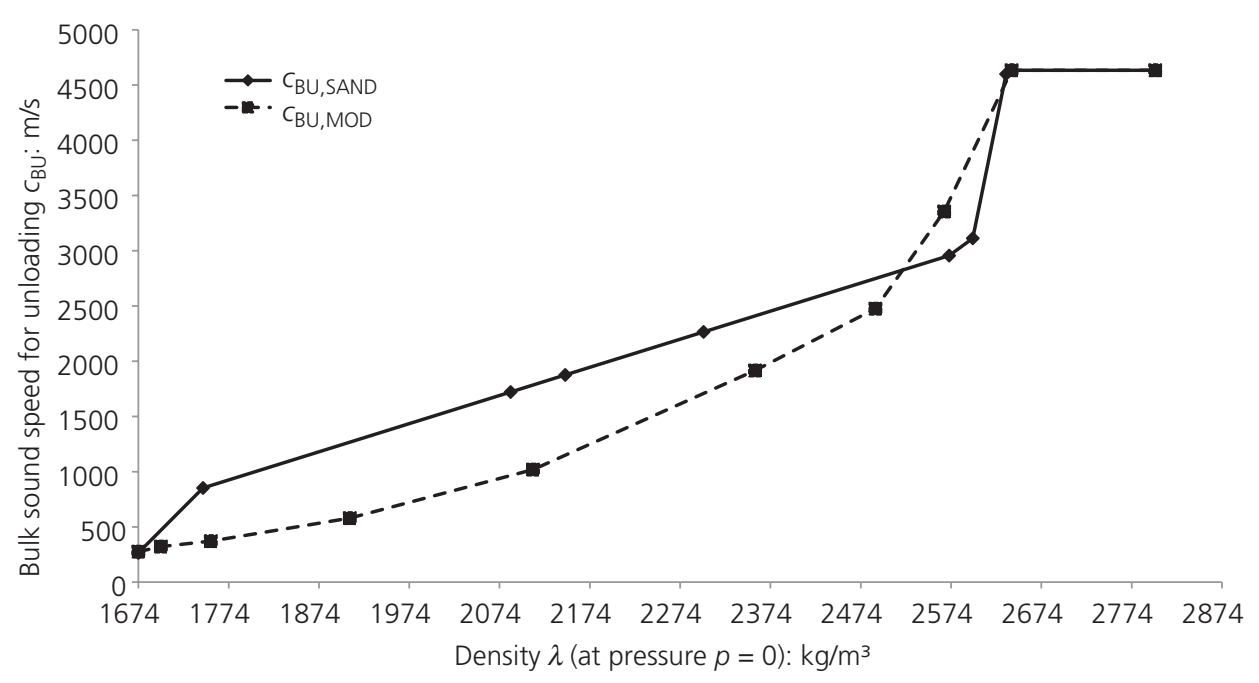

Figure 10. Bulk sound speed for unloading $C_{B U}(\lambda)$ - comparison of the original Sand model and the modified EOS

consistent with the bulk sound speed $c_{\mathrm{BU}}$, the definition of shear modulus $G_{\mathrm{U}}$ was modified as well using Equation 21 and $v=$ $0 \cdot 23$. In Figure 12 the shear modulus $G_{\mathrm{U}, \mathrm{SAND}}(\lambda)$ of the original Sand model and the new, modified $G_{\mathrm{U}, \mathrm{MOD}}(\lambda)$ curve are depicted.

20. $Y=Y(p)+Y(\rho)$

21. $G_{\mathrm{U}}(\lambda)=\frac{3}{2} K_{\mathrm{U}} \frac{1-2 v}{1+v}=\frac{3}{2} \lambda c_{\mathrm{BU}}^{2} \frac{1-2 v}{1+v}$

The failure model used in the Sand model is the hydrotensile limit, which was set to a minimum pressure of $p_{\min }=-1 \mathrm{kPa}$. The criterion simply states that the cell cannot bear shear stresses when $p_{\min }$ is reached.

\section{D wedge simulations: convergence and calibration of} the soil material

Sand has a certain (pressure-dependent) shear strength that is accounted for by a strength model. Therefore, the material model for sand is much more complicated than the ones for air and for TNT, which consist only of equations of state. Thus, sand was seen to be the decisive material for a convergence study. To save computation time, convergence was checked using a 1D wedge model, which is a $1 \mathrm{D}$, spherically symmetric model (Figure 13). It is defined by inner and outer radii $r_{\mathrm{i}}$ and $r_{\mathrm{a}}$ as well as the number of cells $n$ in the direction of radius (Figure 14). As $r_{\mathrm{i}}$ must be

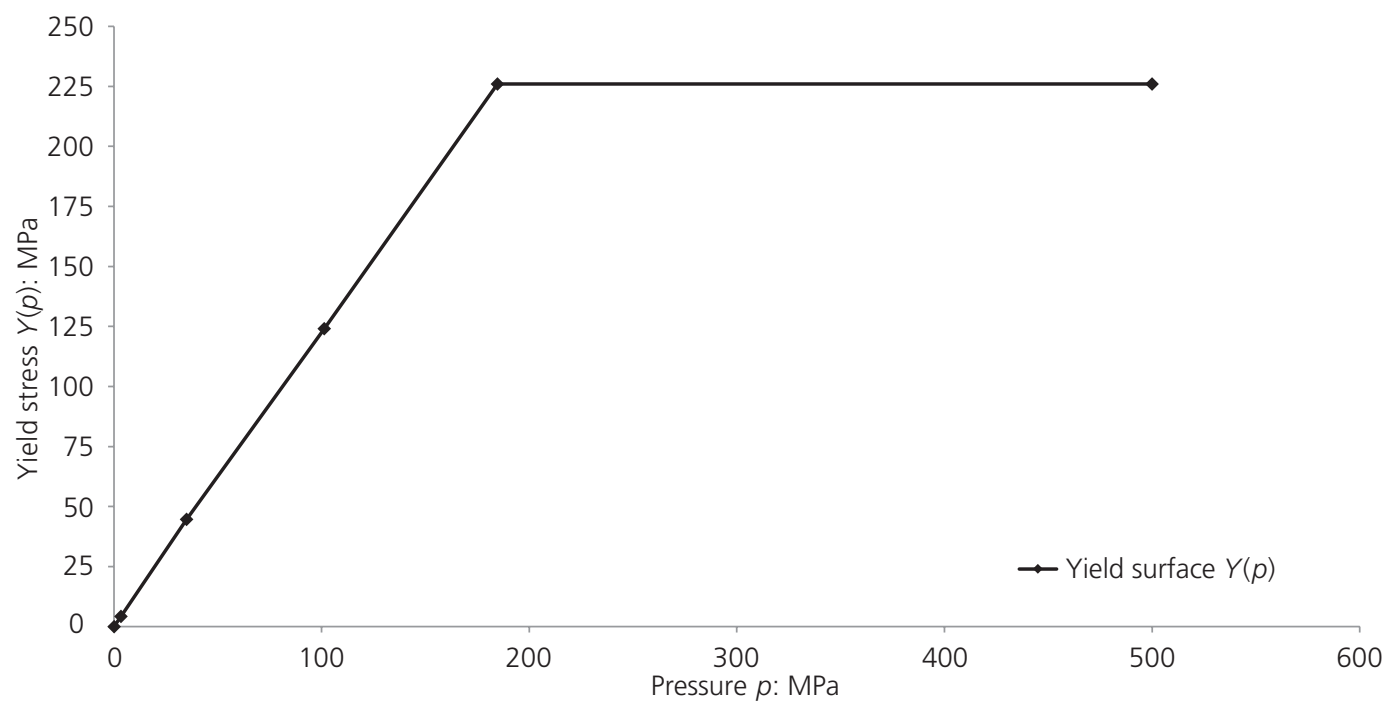

Figure 11. Yield surface $Y(p)$ for the Sand model 


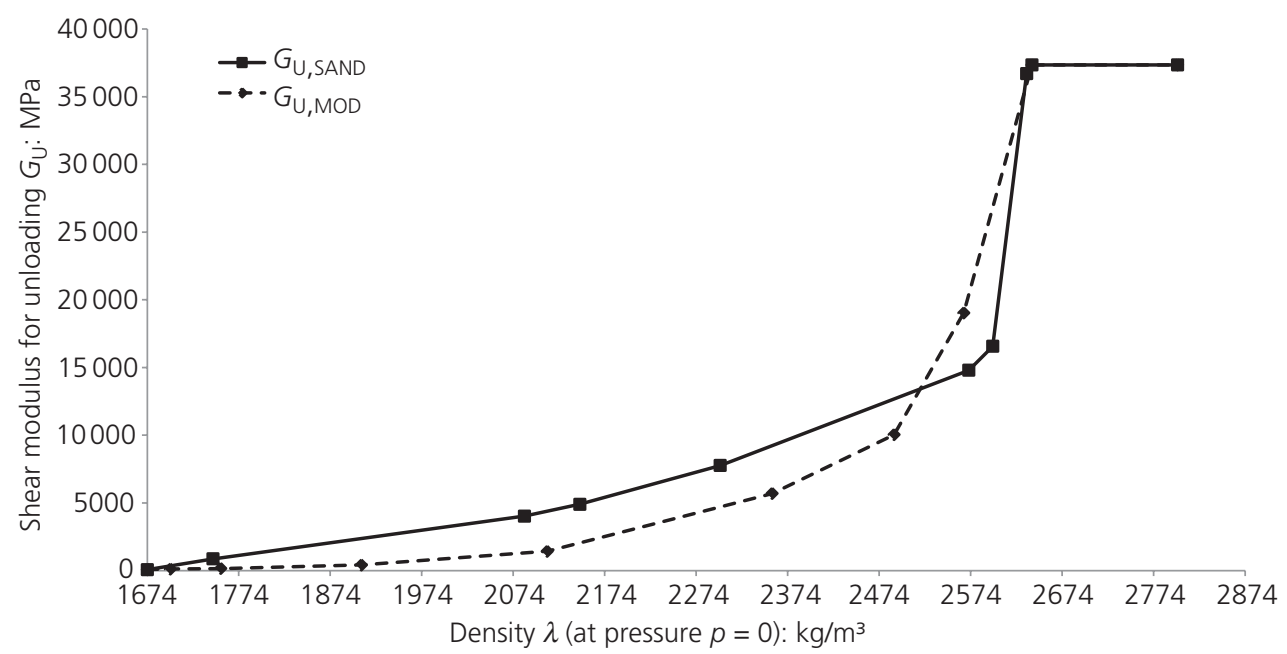

Figure 12. Shear modulus for unloading $G_{U}(\lambda)$ - comparison of the original Sand model and the modified EOS

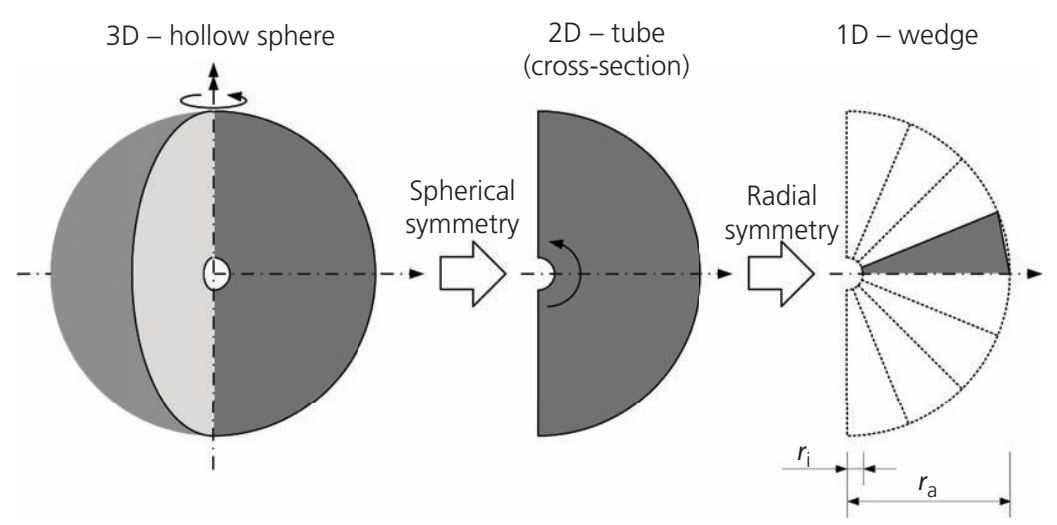

Figure 13. 1D wedge model for spherically symmetric problems

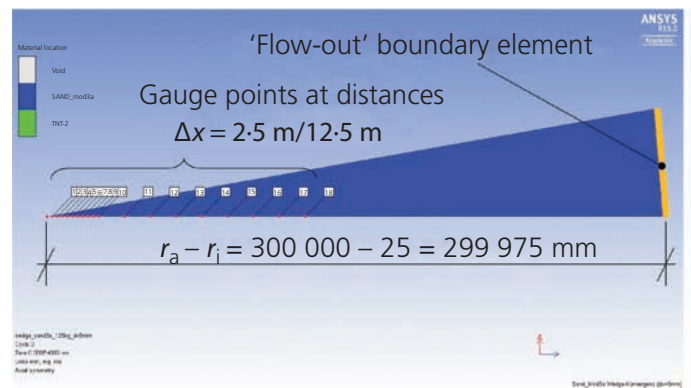

(a)

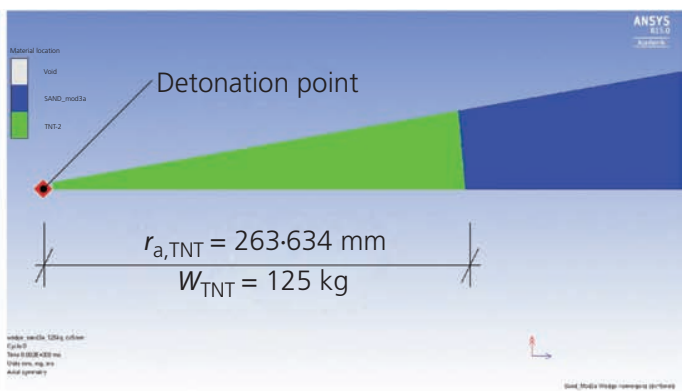

(b)

Figure 14. 1D-wedge model for convergence study (cells not depicted): (a) complete model, (b) inner model with TNT charge 
greater than zero, the 1D wedge model represents a hollow sphere. The explosive charge weight $W_{\mathrm{TNT}}$ is defined by filling the inner part of the wedge from $r_{\mathrm{i}}$ to $r_{\mathrm{a}, \mathrm{TNT}}$. Simulations were done with the following parameters

n inner radius $r_{\mathrm{i}}=25 \mathrm{~mm}$

auter radius $r_{\mathrm{a}}=300000 \mathrm{~mm}=300 \mathrm{~m}$

- explosive's outer radius $r_{\mathrm{a}, \mathrm{TNT}}=263.634 \mathrm{~mm}$ (equivalent to a charge weight $W_{\mathrm{TNT}}=125 \mathrm{~kg}$ for the initial density $\rho_{0, \mathrm{TNT}}=$ $1.63 \mathrm{~g} / \mathrm{cm}^{3}$ )

v variation in the number of elements in the range $2000 \leq n \leq$ 60000 (according to cell sizes $150 \mathrm{~mm} \geq \mathrm{d} x \geq 5 \mathrm{~mm}$ ).

Gauge points for recording the time courses of pressure $p(t)$ were set at a regular distance of $\Delta x=2.5 \mathrm{~m}$ in the range of $x \leq 25 \mathrm{~m}$ and $\Delta x=12 \cdot 5 \mathrm{~m}$ in the range of $25 \mathrm{~m} \leq x \leq 125 \mathrm{~m}$. To extend the period of time during which the time courses could be recorded, the outer edge of the model was chosen to be much greater than the distance $x$ of the outermost gauge point. Additionally, flow-out boundary elements were used at the outer edge of the model to reduce unwanted reflections further.

Figure 15 depicts the calculated peak pressures $p_{1, \max }$ in the range of $75 \mathrm{~m} \leq x \leq 125 \mathrm{~m}$ depending on the cell size $\mathrm{d} x$. For a cell size of $\mathrm{d} x=12.5 \mathrm{~mm}$, the solution seems to have converged. However, aside from the peak values, the time courses need to be checked as well. As can be seen in Figure 16, depending on the cell size $\mathrm{d} x$, a threshold $p_{\text {lim }}$ exists below which the time courses start to oscillate. For pressures smaller than $p_{\text {lim }}$, the chosen material model for sand with Compaction EOS linear, the Mo Granular strength model and the hydrotensile limit failure model obviously does not work properly. For a cell size of $\mathrm{d} x=$
$12.5 \mathrm{~mm}$, this seems to be the case for pressures $p \leq p_{\lim }=$ $0.3 \mathrm{kPa}$. As the free surface is stress-free, there will always be some inevitable numerical noise with the chosen material model. A cell size of $\mathrm{d} x=12.5 \mathrm{~mm}$ was chosen for the two-dimensional (2D) simulations, as this seemed be an acceptable compromise between computation time and the necessary accuracy down to very low pressures and stresses.

Due to the fragmentary state of knowledge concerning soil behaviour at high strain rates, the numerical results should always be compared with experimental data or at least empirical models. For the latter, the widely used empirical model by Drake and Little (1983), according to Equation 22 and Table 1, as well as the improved version by Drake et al. (1989), given by Equations 23-25 and Table 2, were chosen. For a discussion of both models, the reader is referred to the work by Laine (2012). As the 1D wedge model is valid for the entire space (i.e. no boundaries and reflections etc.), the ground-shock coupling factor $f$ in Equations 22 and 24 was set to $f=1$, which simply means that the explosive energy is completely transferred into the soil. Comparison was done for the peak pressure $p_{1, \max }$. Very good agreement was achieved for the new model by Drake et al. (1989) and mediumdense, dry sand (Figure 17).

22.

$$
\begin{aligned}
p_{1, \max }\left[\mathrm{N} / \mathrm{m}^{2}\right]= & 48.768 f \rho\left[\mathrm{kg} / \mathrm{m}^{3}\right] \times c[\mathrm{~m} / \mathrm{s}] \\
& \times\left(2.7997 \frac{r[\mathrm{~m}]}{\sqrt[3]{W_{\mathrm{TNT}}[\mathrm{kg}]}}\right)^{-n}
\end{aligned}
$$

23. $p_{1, \text { max }}=\rho_{0} v_{\mathrm{S}, \max } v_{1, \text { max }}$

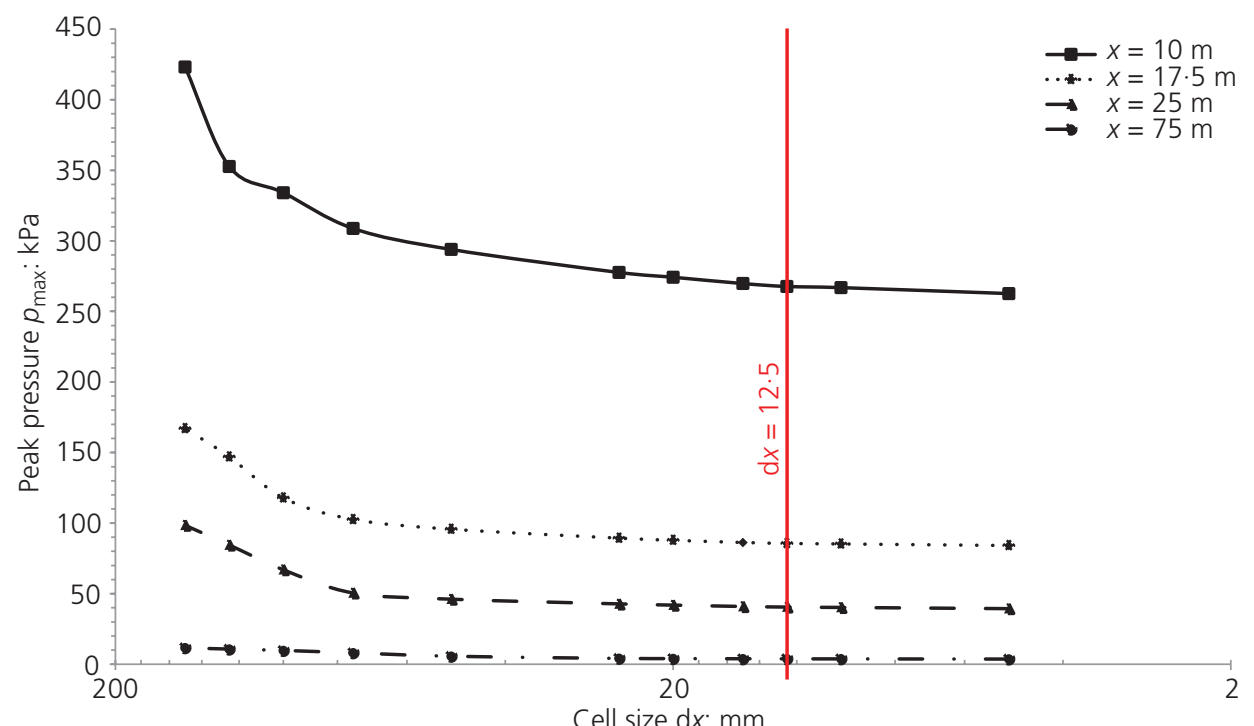

Figure 15. Convergence study - peak pressures $p_{1, \max }$ in the range of $10 \mathrm{~m} \leq x \leq 75 \mathrm{~m}$ depending on the cell size $\mathrm{d} x$ 


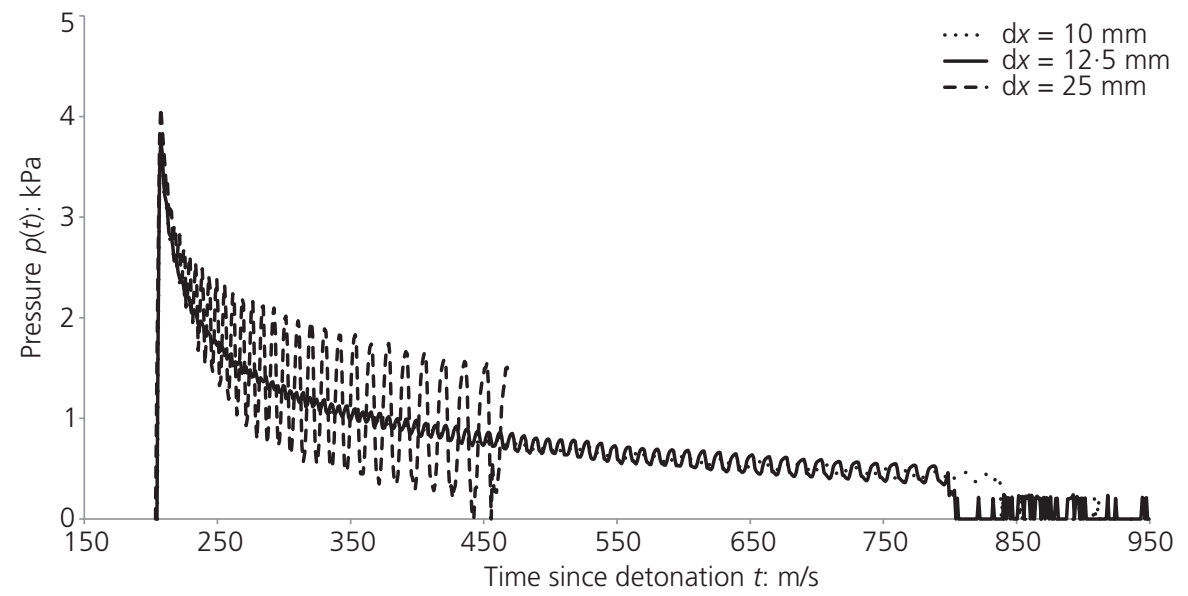

Figure 16. Convergence study - time courses of pressure $p(t)$ at a distance $x=75 \mathrm{~m}$ from the centre of explosion for different cell sizes $\mathrm{d} x$

24. $v_{1, \max }[\mathrm{m} / \mathrm{s}]=\frac{9906}{\sqrt{\rho_{0}}} f\left(\frac{r}{0 \cdot 155 W_{\mathrm{TNT}}^{1 / 3}}\right)^{-n}$
25. $v_{\mathrm{S}, \max }=c_{0}+S_{1} v_{1, \max }$
with $S_{1}=1 \cdot 5$

\section{Modelling strategy}

The modelling strategy had to meet the following criteria

- accurate illustration of explosion, the interaction between explosives and the surrounding soil and the temporal evolution of the explosion wave

- tracking of the blast wave to the (unknown) abatement distance, above which a wave impact is negligible

- compliance with the fineness of the mesh required for convergence, considering the maximum number of $4 \times 10^{6}$ processable cells in Autodyn

- prevention of unwanted reflections at the model edges.

Due to the charge mass of $125 \mathrm{~kg}$, a rather large abatement distance was to be expected in the present case. The necessary

\begin{tabular}{lccc}
\hline Type of soil & $\rho: \mathrm{kg} / \mathrm{m}^{3}$ & c: $\mathrm{m} / \mathrm{s}$ & $n$ \\
\hline Dry sand, loose & 1500 & 180 & $3 \cdot 10$ \\
Dry sand, medium-dense & 1700 & 300 & $2 \cdot 75$ \\
Dry sand, dense & 1950 & 520 & $2 \cdot 50$ \\
\hline
\end{tabular}

Data according to Laine (2012)

Table 1. Parameters for the empirical model by Drake and Little (1983) model dimensions in combination with the cell size necessary for a convergent solution would have resulted in a number of cells far larger than the available $4 \times 10^{6}$. Simulations within a single overall model were thus excluded.

In the first step, the explosion, the interaction between the explosives and the surrounding soil and the undisturbed wave propagation in the entire space - until shortly before the arrival of the shock wave at the ground level and the resulting reflection as a relaxation wave - were simulated using a $1 \mathrm{D}$ wedge model. The utilisation of the twofold radial symmetry in the 1D wedge model corresponds to the specification of a spherical explosive charge in a 2D model (Figure 13). Since the models were very small, with an outer radius equal to the depth of the charge $r_{\mathrm{a}}=d_{\mathrm{TNT}}=$ $\{0.5 \mathrm{~m} ; 1.0 \mathrm{~m} ; 1.5 \mathrm{~m} ; 2.0 \mathrm{~m}\}$, a small element width could be chosen. Thus, the spatial and the temporal resolution are accordingly high, and the above-mentioned first criteria point is met. The solution of the $1 \mathrm{D}$ wedge model was transferred to a radially symmetric $2 \mathrm{D}$ model by remapping.

In order to observe the shock wave further, the modelling strategy of the 'moving window', which is described in the following, was developed. Here, the radially symmetric 2D model is constructed in sections with a constant element width $\mathrm{d} y$ in the horizontal direction (note: in radially symmetric Autodyn models, the $x$ axis

\begin{tabular}{lccc}
\hline Type of soil & $\rho_{0}: \mathrm{kg} / \mathrm{m}^{3}$ & $c_{0}: \mathrm{m} / \mathrm{s}$ & $n$ \\
\hline Dry sand, loose & 1500 & 180 & $2 \cdot 75$ \\
Dry sand, medium-dense & 1700 & 300 & $2 \cdot 30$ \\
Dry sand, dense & 1950 & 520 & $2 \cdot 10$
\end{tabular}

Table 2. Parameters for the empirical model by Drake et al. (1989) 


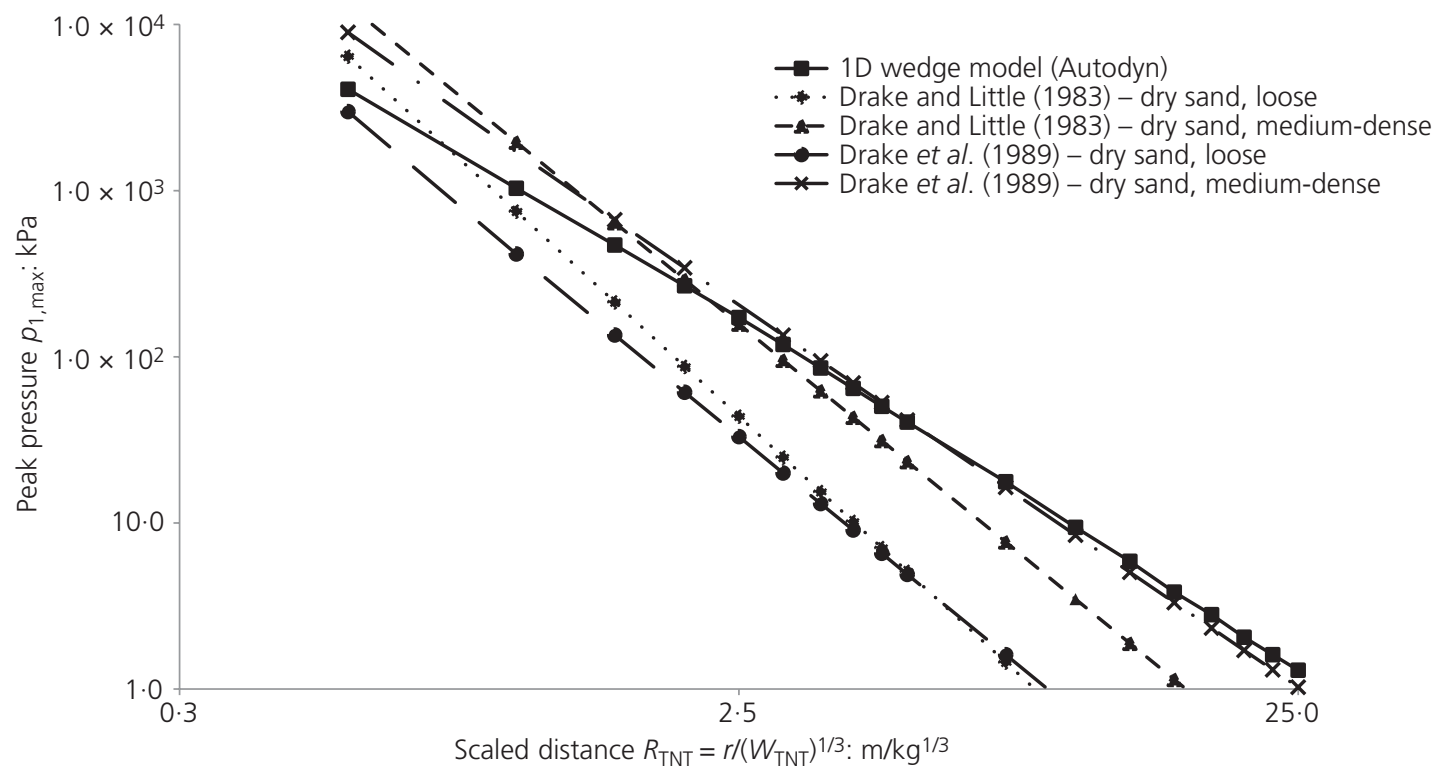

Figure 17. Comparison of peak pressure $p_{1, \max }\left(R_{\mathrm{TNT}}\right)$ - numerical 1D wedge model against empirical models by Drake and Little (1983) and Drake et al. (1989)

is the axis of symmetry by default). Each section consists of three model areas as shown in Figure 18. The central model area is finely meshed according to the convergence study. Sufficiently long run-out areas are located above and below the central area to prevent reflections at the upper and lower model boundaries. The element height $\mathrm{d} x$ of the run-out areas increases towards the respective model boundaries, allowing for a lower amount of elements. The model areas within a section are coupled to

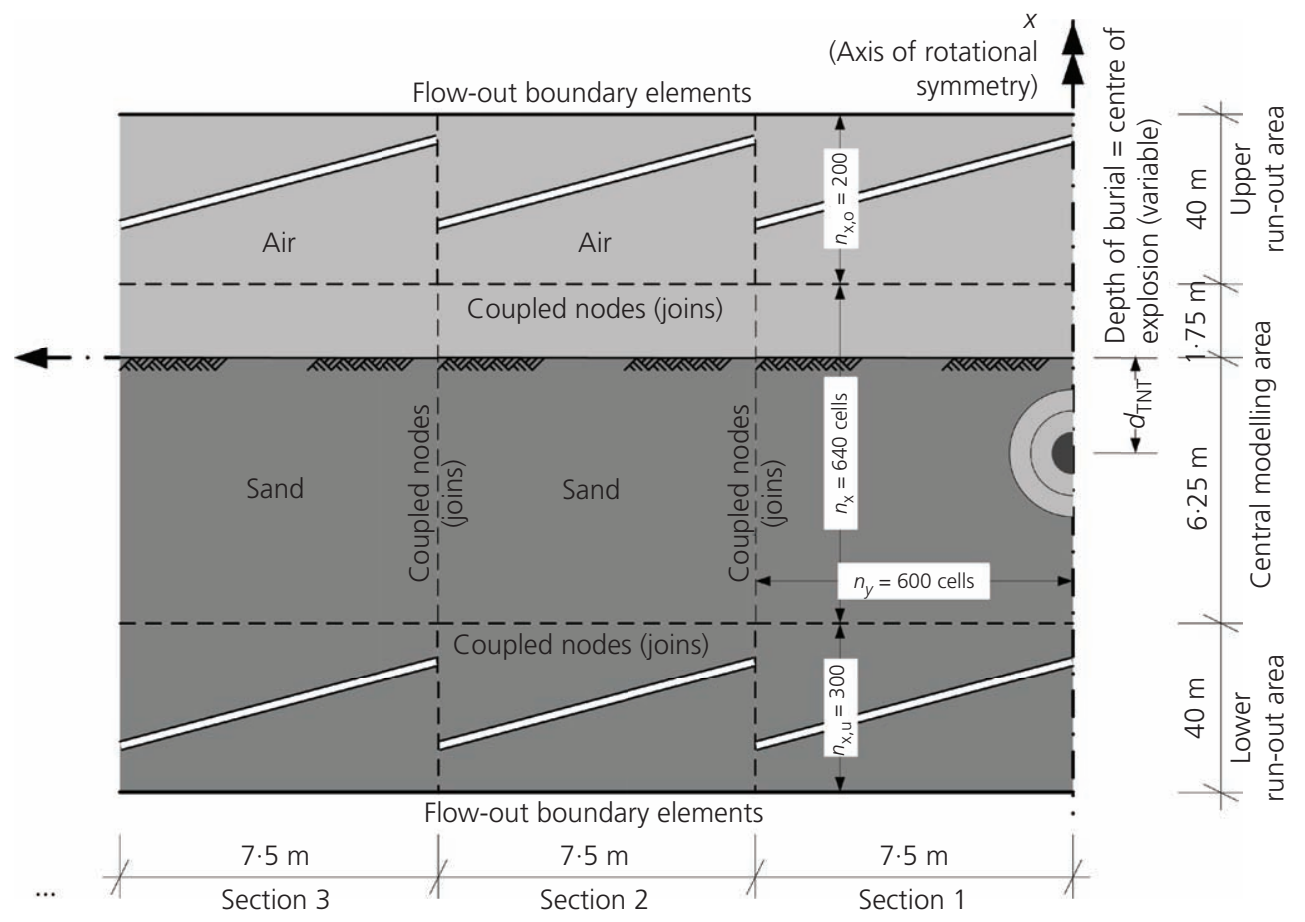

Figure 18. 2D model structure for the modelling strategy of the 'moving window' 
Geotechnical Research

Volume 3 Issue 3
Underground explosions: estimating the

safe distance

Zimbelmann and Boley

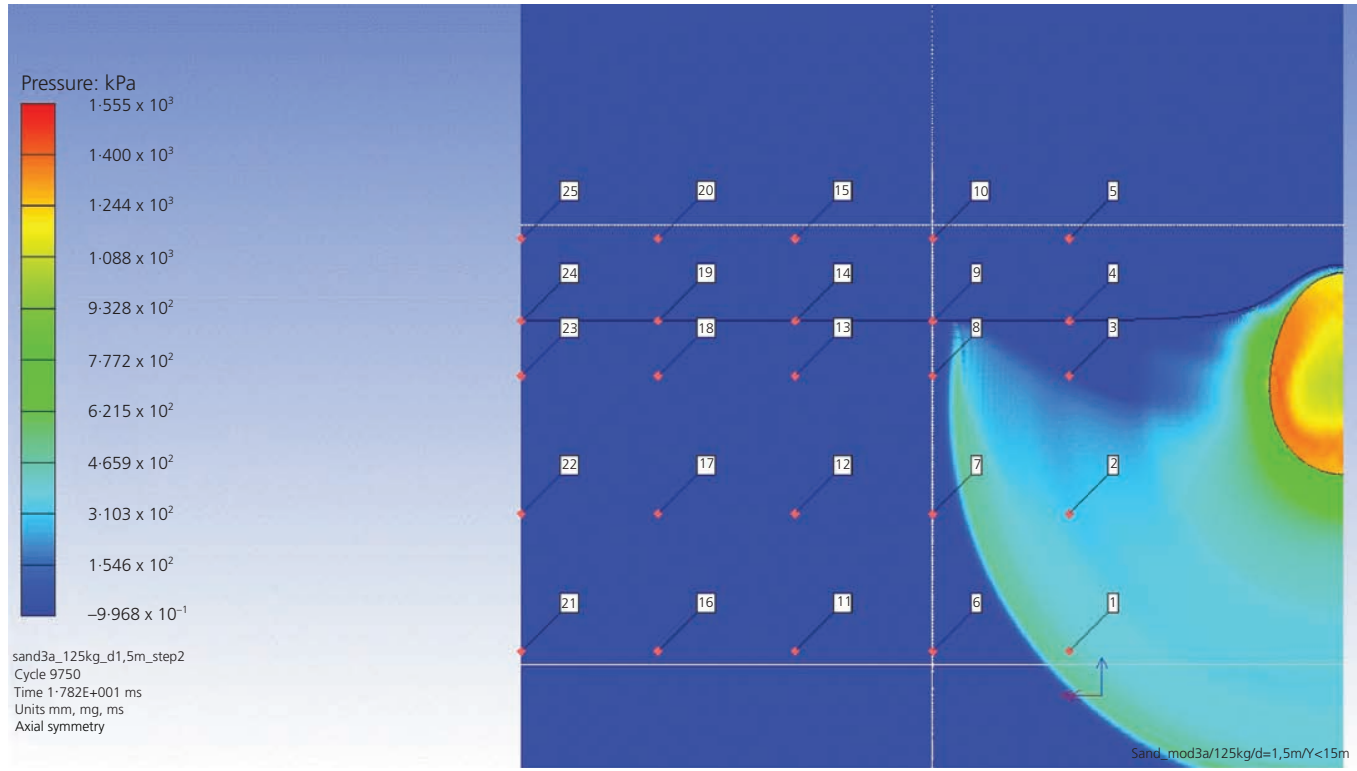

Figure 19. Simulation for $d_{\mathrm{TNT}}=1.5 \mathrm{~m}$ at the beginning of simulation step number 2 (with gauges 1-25) - here: pressure $p$

the mutual nodes. In the simulations carried out, the following provisions with regard to the geometry have been taken

section width $\Delta y=7.5 \mathrm{~m}$ and the corresponding element width $\mathrm{d} y=12.5 \mathrm{~mm}=$ const. in accordance with the convergence study

- central modelling area: height $\Delta x=8 \mathrm{~m}$ with $-6 \cdot 25 \mathrm{~m} \leq x \leq$ $1.75 \mathrm{~m}$ and the ground surface at $x=0$, element width $\mathrm{d} x=$ $12.5 \mathrm{~mm}$ in accordance with the convergence study run-out areas: respective height $\Delta x=40 \mathrm{~m}$ with $n_{x, \mathrm{o}}=$ 200 cells for the upper run-out area and $n_{x, \mathrm{u}}=300$ cells for the lower one

At the beginning of the simulation, only the first section was modelled. Shortly before the wave's arrival at the outer edge of the section, the calculation was interrupted. An additional section was then appended, and the common nodes of the first and the new section were coupled. After the maximum processable cell

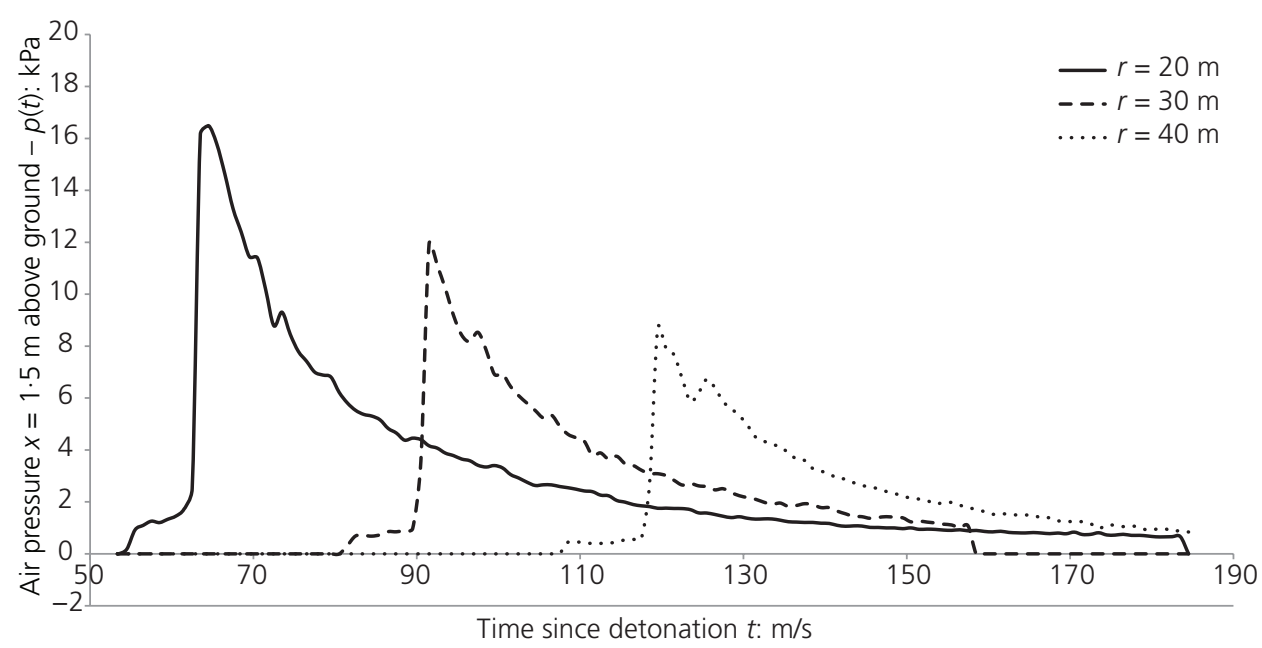

Figure 20. Time courses of air pressure $p_{1}(t)$ in $x=1.5 \mathrm{~m}$ above ground level (exemplarily for $d_{\mathrm{TNT}}=1.0 \mathrm{~m}$ and horizontal distances $\left.20 \mathrm{~m} \leq r_{\text {hor }} \leq 40 \mathrm{~m}\right)$ 
Underground explosions: estimating the

safe distance

Zimbelmann and Boley

\begin{tabular}{ccccc}
\hline & $d_{\mathrm{TNT}}=0.5 \mathrm{~m}$ & $d_{\mathrm{TNT}}=1.0 \mathrm{~m}$ & $d_{\mathrm{TNT}}=1.5 \mathrm{~m}$ & $d_{\mathrm{TNT}}=2.0 \mathrm{~m}$ \\
\hline$A$ & 424.5831 & 138.9259 & 73.1186 & 123.513 \\
$B$ & -5.4874 & -83.4362 & -56.2163 & -112.2835 \\
$n$ & -0.8349 & -0.1089 & -0.0525 & -0.0204
\end{tabular}

Table 3. Coefficients $A, B$ and $n$ in Equation 26 for different depths of burial

number was reached - in the present case, with five sections - the respective innermost section was deleted before a new section was added (see Figure 18). This enabled a wave section with a width of $30 \mathrm{~m}$, correspondingly four sections, to be traced to the initially unknown abatement distance. Additionally, in the first four stages of simulation, the number of elements could thus be kept low and computing time could be saved.

Gauge points were arranged in a regular grid of $2.5 \mathrm{~m} \times 2.5 \mathrm{~m}$. This is where the time courses of the observed damage patterns were recorded (Figure 19). A total of four separate simulations were performed, corresponding to the investigated charge depths $d_{\mathrm{TNT}}=\{0.5 \mathrm{~m} ; 1.0 \mathrm{~m} ; 1.5 \mathrm{~m} ; 2.0 \mathrm{~m}\}$.

\section{Assessing the impact of underground explosions on buildings}

Preliminary remarks

In the following, a method of generating a decision aid is introduced, with which the effects of underground explosions

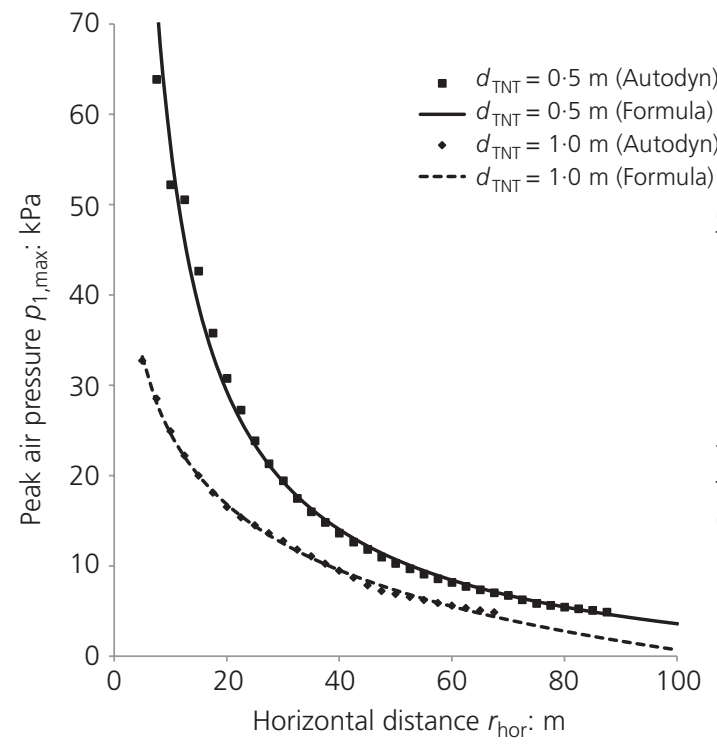

Figure 21. Peak air pressure $p_{1, \max }$ in $x=1.5 \mathrm{~m}$ above ground level as a function of horizontal distance $r_{\text {hor }}$ - comparison of the numerical Autodyn values with the approximated values according to Equation 26 and Table 3 on above-ground buildings with shallow foundations can be estimated. This decision aid consists of a diagram showing the safe distance $r_{\text {hor,safe, }}$, in which a building will remain undamaged by an explosion. It applies to loose and medium-dense, dry sand, an explosive charge weight of $W=125 \mathrm{~kg}$ TNT and depths of burial $0.5 \mathrm{~m} \leq d \leq 2.0 \mathrm{~m}$. The following damage patterns were taken into account

- air blast and forced vibrations

- foundation-induced excitation of the structure to vibrations

- inadmissible inclination of foundations due to subsidence.

The shock wave parameters corresponding to the failure modes are air pressure $p$, horizontal particle velocity $v_{\text {hor }}$ and shear deformation $\gamma_{x y}$.

Since the decision aid is intended to apply to different types of structures, a decoupled analysis is carried out and the structure itself is not modelled. The interaction between the shock wave in air and soil and the structure is registered through permissible thresholds for the relevant shock wave parameters, which are based on empirical analyses.

\section{Evaluation of the calculated time courses}

Since the Autodyn simulations were performed only for a charge mass $W_{\mathrm{TNT}}=125 \mathrm{~kg}$, the influence of the distance and the depth of the charge is given in the unscaled values $r_{\text {hor }}$ and $d_{\text {TNT }}$.

\section{Criterion number 1: 'air blast'}

For all four charge depths $d_{\mathrm{TNT}}=\{0.5 \mathrm{~m} ; 1.0 \mathrm{~m} ; 1.5 \mathrm{~m} ; 2.0 \mathrm{~m}\}$, the time courses of air pressure $p_{1}(t)$ at a height of $x=1.5 \mathrm{~m}$

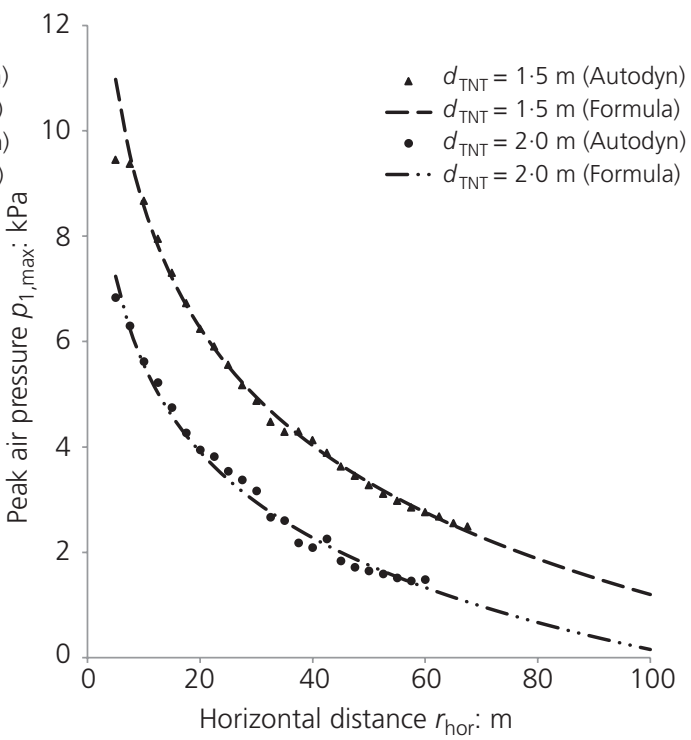


Geotechnical Research

Volume 3 Issue 3
Underground explosions: estimating the

safe distance

Zimbelmann and Boley $p_{1, \text { max }}: \mathrm{kPa}$

Extent of damage

\begin{tabular}{ll}
\hline $2 \cdot 5$ & Destruction of $50 \%$ of all windows \\
5 & Destruction of $75-100 \%$ of all windows \\
10 & Destruction of $100 \%$ of all windows \\
20 & Destruction of brick walls \\
50 & Destruction of multistorey buildings \\
70 & Destruction of reinforced concrete walls
\end{tabular}

Table 4. Extent of damage depending on the free-field peak overpressure in air (Steidinger and Krüning, 1991)

above ground were recorded at the gauge points (Figure 20). From these time courses, the maximum values $p_{1, \max }=f\left(r_{\text {hor }}\right)$ were determined, which can be approximated quite well by way of the exponential equation in Equation 26. The corresponding coefficients $A, n$ and $B$ in Table 3 were calculated by minimising the error squares. The comparison of the numerical values with the peak air pressures calculated by the approximation formulas shows a very good agreement (Figure 21).

26. $p_{1, \max }[\mathrm{kPa}]=A\left(r_{\text {hor }}[\mathrm{m}]\right)^{n}+B$

Using numerous evaluations of explosion accidents as well as observations during wartime, it could be shown that there is a relationship between the peak air overpressure $p_{1, \max }$ and the extent of damage. Examples for such empirical thresholds are shown in Table 4. Depending on the author or literature, these thresholds are subject to a certain degree of spread. This is due to the fact that they are empirical values from all over the world and from different time periods.
Solving Equation 26 by the horizontal distance gives the horizontal distance $r_{\text {hor,safe }}$ (Equation 27) for a defined permissible peak air pressure, above which the existing peak pressure in air falls below the empirical, permissible value $\left(p_{1, \mathrm{ex}} \leq p_{1, \mathrm{perm}}\right)$. In accordance with the North Atlantic Treaty Organization manual (Nato, 2010), a value of $p_{1, \text { perm }}=5 \mathrm{kPa}$ was selected. The corresponding curve of the safe distance $r_{\text {hor,safe }}=f\left(d_{\mathrm{TNT}}\right)$ depending on the charge depth $d_{\mathrm{TNT}}$ is shown in Figure 22.

27. $r_{\text {hor }} \geq r_{\text {hor,safe }}[\mathrm{m}]=\left(\frac{p_{1, \max }[\mathrm{kPa}]-B}{A}\right)^{1 / n}$

\section{Criterion number 2: 'foundation-induced excitation of the structure to vibrations'}

The procedure hereinafter described and shown in Figure 23 corresponds essentially to the method according to DIN 4150-3 (DIN, 1999). For different horizontal distances $r_{\text {hor }}$, the following steps need to be taken

E calculation of the Fourier spectrum $v_{\text {Ampl }}(f)$ of the horizontal particle velocity or rather the amount spectrum $\left|v_{\text {Ampl }}(f)\right|$ by means of discrete Fourier transform (DFT) according to Equation 28

- normalisation of the spectrum according to Equation 29 with respect to its maximum spectral value at the main frequency $f^{*}$

- comparison of the normalised spectrum multiplied by the maximum value of the particle velocity $v_{\text {hor,max }}$ and the permissible range; the safe distance safe $r_{\text {hor,safe }}$ is reached when Equation 30 is fulfilled.

$$
\begin{aligned}
v_{\text {hor }}(t) & =v_{\text {hor }}[n] \\
28 . \quad & \Rightarrow \operatorname{DFT}\left\{v_{\text {hor }}[n]\right\}=v_{\text {Ampl }}[m]=v_{\text {Ampl }}(f)
\end{aligned}
$$

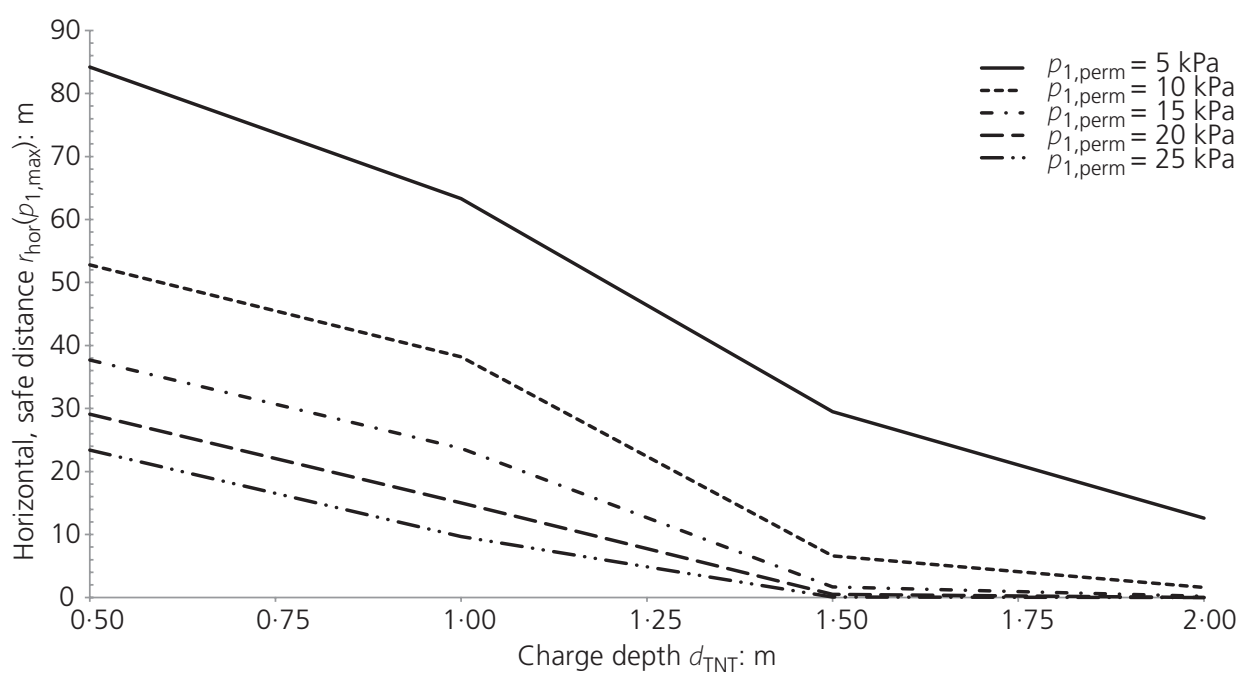

Figure 22. Air pressure (criterion number 1) - safe horizontal

distance $r_{\text {hor, safe }}$ as a function of charge depth $d_{\text {TNT }}$ 
1. Numerical simulation (free field)

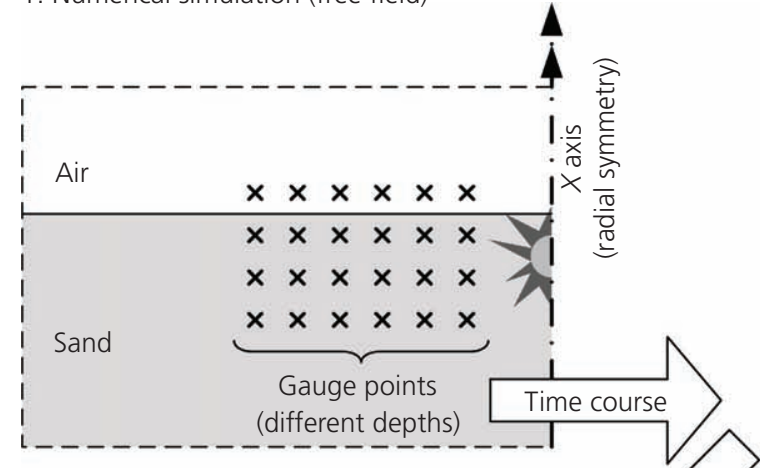

3. Normalized spectrum of particle velocity

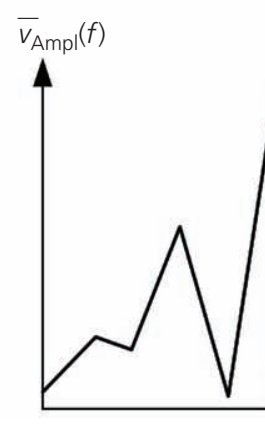

2. Horizontal particle velocity $v_{y}(t)$

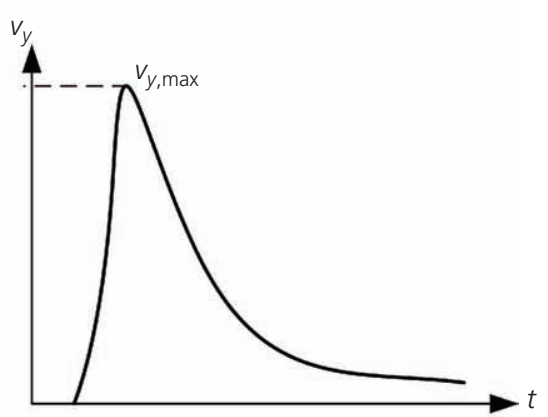

4. Comparison with permissible values

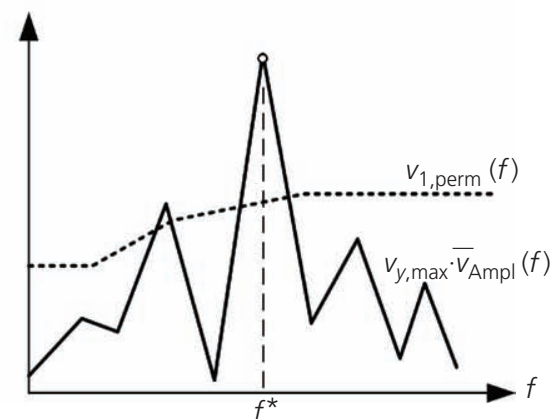

Figure 23. Procedure in accordance with DIN 4150-3, appendix D.2 (DIN, 1999)

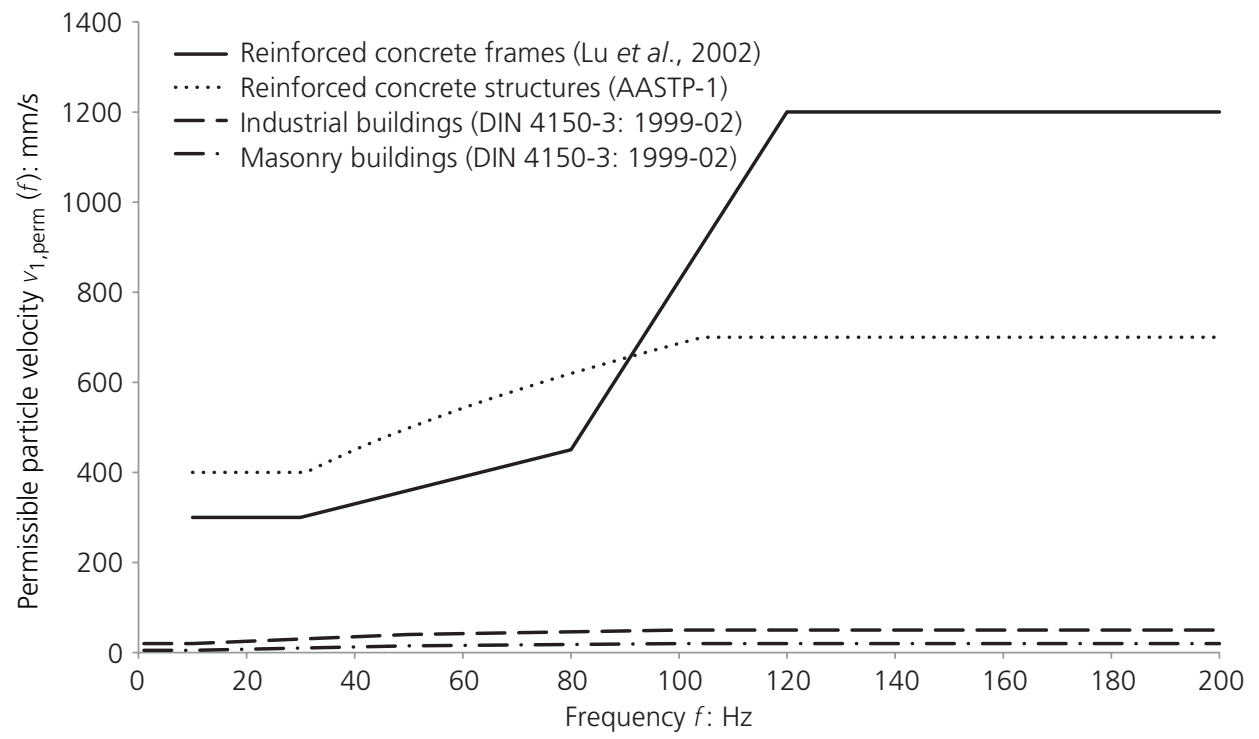

Figure 24. Permissible particle velocity spectra $v_{1, \text { perm }}(f)$ by Lu et al. (2002), AASTP-1 (Nato, 2010) and DIN 4150-3 (DIN, 1999) 
Underground explosions: estimating the

safe distance

Zimbelmann and Boley
29. $\quad \bar{v}_{\mathrm{Ampl}}(f)=\frac{v_{\mathrm{Ampl}}(f)}{\max \left\{v_{\mathrm{Ampl}}(f)\right\}}=\frac{v_{\mathrm{Ampl}}(f)}{v_{\mathrm{Ampl}}\left(f^{*}\right)}$

30. $v_{\text {hor,max }} \bar{v}_{\text {Ampl }}\left(f^{*}\right) \leq v_{1, \text { perm }}\left(f^{*}\right)$

The following preliminaries need to be carried out for the DFT

- smoothing of time courses to reduce noise and unrealistic frequencies

- conversion of the numerically determined time courses to a constant sampling interval $T_{\mathrm{s}}\left(v_{\text {hor }}(t) \rightarrow v_{\text {hor }}\left(t_{n}\right), t_{n}=n T_{\mathrm{s}}\right.$, $n \in N$ )

- zero padding: an expansion of the signal sequence $v_{\text {hor }}[n]$ by appending zeros in order to calculate the Fourier spectrum $v_{\text {Ampl }}\left(f_{m}\right)=v_{\text {Ampl }}[m]\left(f_{m}=m \Delta f, m \in N\right)$ with a sufficiently fine resolution

multiplying the signal sequence $v_{\text {hor }}[n]$ with a suitable window sequence $w[n]$ to reduce leakage effects.

Figure 24 is a comparison of different permissible particle velocities $v_{1, \text { perm }}(f)$. The values according to DIN 4150-3 (DIN, 1999) are clearly the most conservative. This is mainly due to the fact that these thresholds preclude any form of damage, while the criteria according to AASTP-1 (Nato, 2010) and Lu et al. (2002) permit damage corresponding to a loss of rigidity by $40 \%$. In the present case, the DIN values for brick residential buildings were used.
The criterion was evaluated at the gauge point depths $x=$ $\{-6.0 \mathrm{~m} ;-3.5 \mathrm{~m} ;-1.0 \mathrm{~m}\}$ below ground level. These depths are roughly equivalent to the foundation levels of buildings with two, one or no sublevels. As shown in Figure 25, the safe distance increases as the foundation level becomes shallower. This is consistent with the fact that surface waves experience significantly less dampening than compression and shear waves and thus have a longer range and therefore a greater destructive potential for shallow foundations. Since surface waves can also induce vibrations in buildings with sublevels, the limit curve corresponding to the foundation level $x=-1.0 \mathrm{~m}$ was used for merging the three damage patterns in Figure 29.

\section{Criterion number 3: 'inadmissible inclination of foundations due to subsidence'}

Subsidence due to dynamic stimulation of the soil such as under machine foundations and traffic infrastructure during earthquakes or even in the far field of explosions is mainly caused by shear strains on passage of shear waves (Hsu and Vucetic, 2004; Vucetic, 1994). This requires a certain sensitivity to vibration and a tendency to grain rearrangements in sand. The plastic distortions start to occur when the linear threshold shear strain $\gamma_{t 1}$ is exceeded. The granular structure collapses completely when the shear strain $\gamma_{x y}$ exceeds the volumetric threshold shear strain $\gamma_{\mathrm{tV}}$. The latter is subject to a certain spread, depending on the plasticity index $I_{\mathrm{p}}$ (Figure 26). For granular soils such as sand and gravel, $I_{\mathrm{p}}$ needs to be set to zero.

The shear strain $\gamma_{x y}$ from the Autodyn simulations are input values for the evaluation with regard to the damage pattern

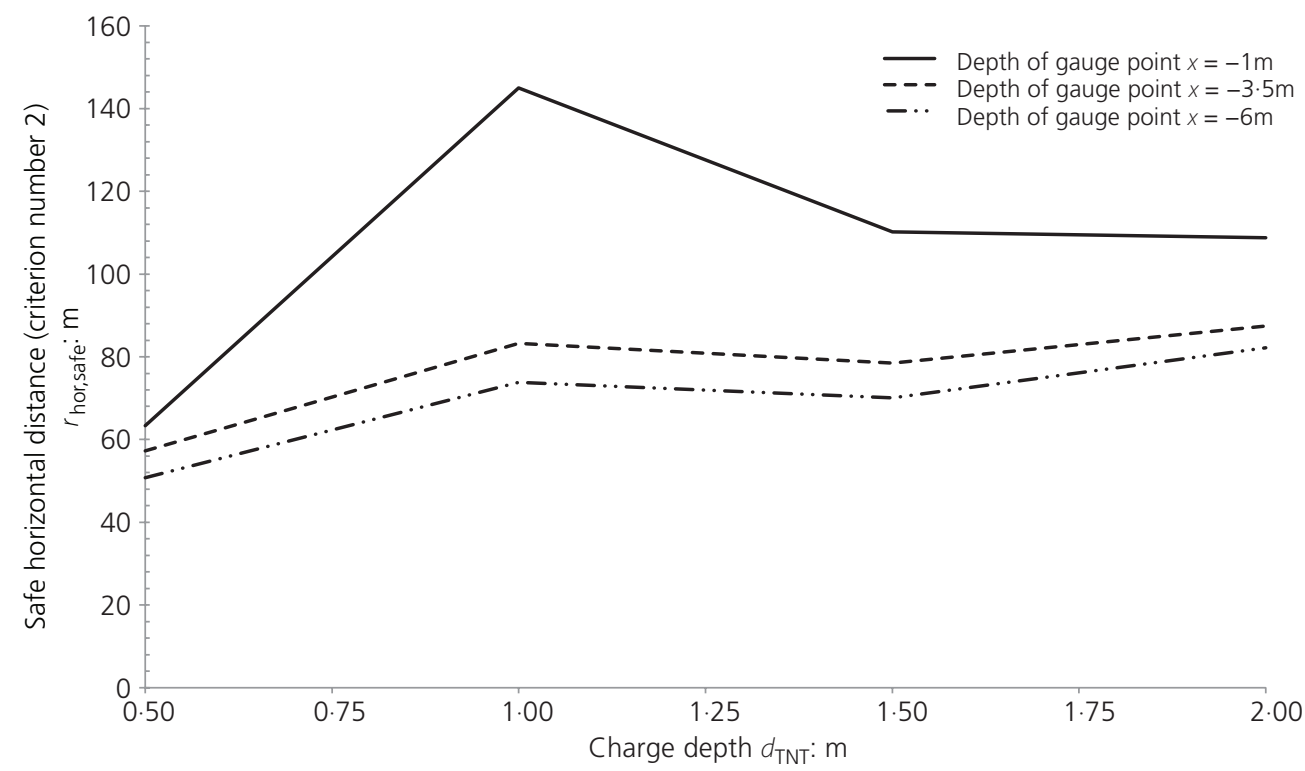

Figure 25. Foundation-induced vibrations (criterion number 2) safe horizontal distance $r_{\text {hor,safe }}$ depending on the charge depth $d_{\text {TNT }}$ and the depth of foundation $x$ 


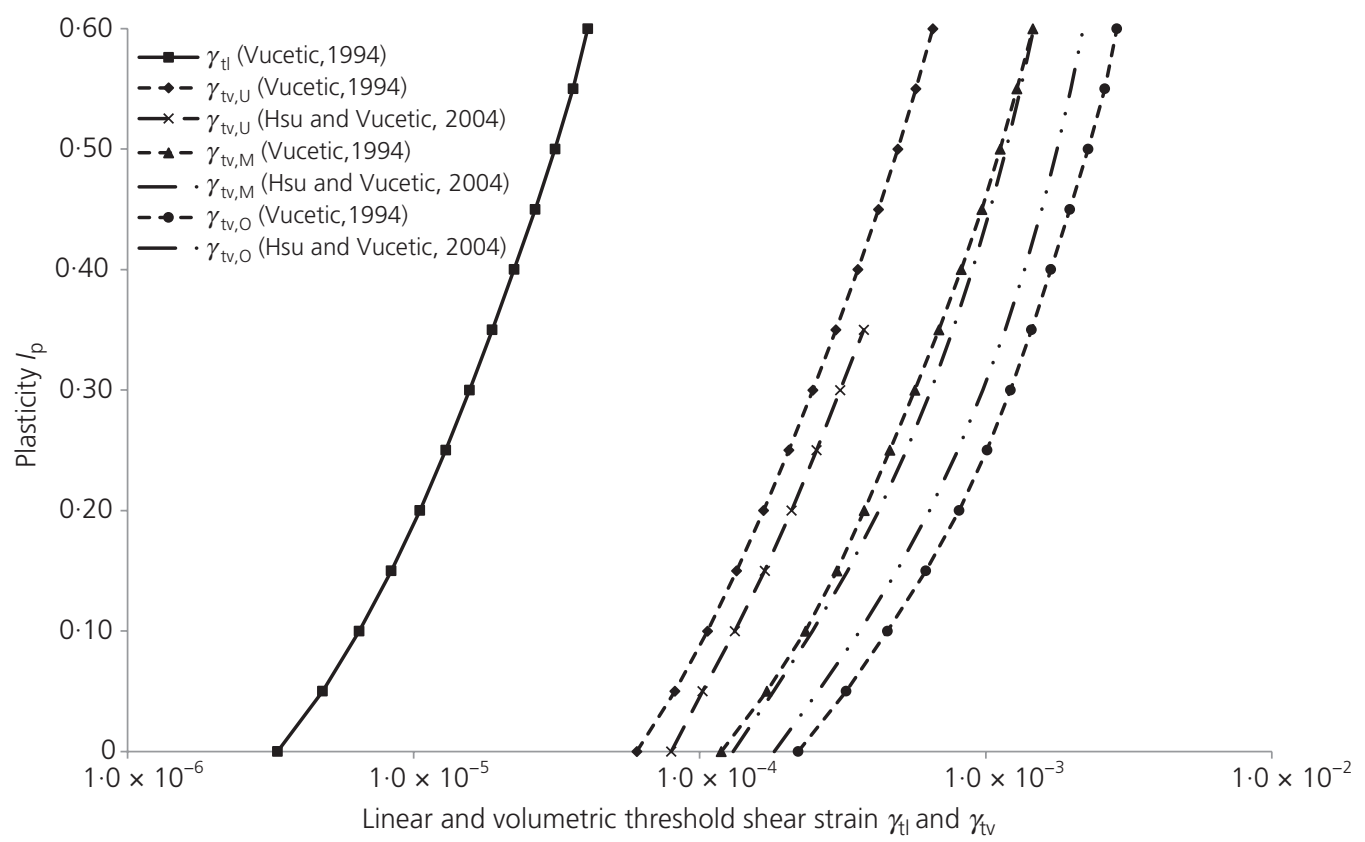

Figure 26. Linear and volumetric threshold shear strain $\gamma_{\mathrm{tl}}\left(I_{\mathrm{p}}\right), \gamma_{\mathrm{tv}}\left(I_{\mathrm{P}}\right)$ (Hsu and Vucetic, 2004; Vucetic, 1994)

'inadmissible angular distortion of foundations due to subsidence'. For quantitative determination of the subsidence, the following two assumptions were made.

- The decrease in volume corresponds to the decrease in the pore volume. The granular structure does not experience a deformation as a result of particle rearrangement.

- A linear relationship exists between the shear strain $\gamma_{x y}$ and the porosity $n_{1}$ after passage of the wave (Equation 31 ). For shear strains $\gamma_{x y} \geq \gamma_{\mathrm{tv}, \mathrm{M}}$, the soil particles undergo particle rearrangement and the maximum relative density is reached.
This corresponds to vertical sagging with a decrease in the porosity to $n_{\min }$. For $\gamma_{x y} \leq \gamma_{\mathrm{t}}$, no sagging occurs and the porosity remains unchanged at the initial value of porosity $n_{0}$.

As shown in Figure 27, vertical distortion $\varepsilon_{x}$ can be calculated in a given point according to Equation 32. Integration over the depth in a certain horizontal distance $r_{\text {hor }}$ from the centre of explosion yields sags (Equation 33). In the present case, the integration was carried out only in the depth range $-6 \mathrm{~m} \leq x \leq-1 \mathrm{~m}$, corresponding to the depths of the integration points in the numerical model.

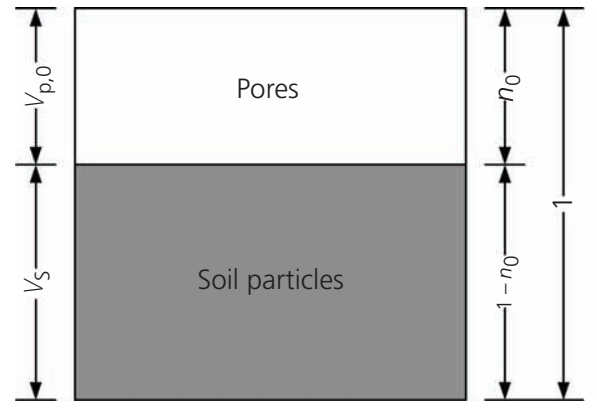

(a)

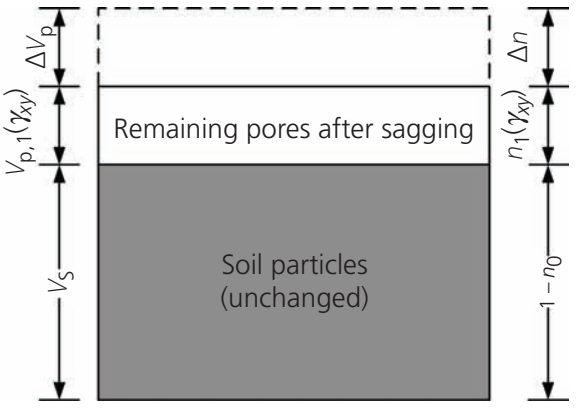

(b)

Figure 27. Change in porosity $n$ as a result of sagging: (a) initial state, (b) state after shearing with $\gamma_{x y}>\gamma_{t \mid}$ 
Underground explosions: estimating the

safe distance

Zimbelmann and Boley

$$
\begin{aligned}
n_{1}\left(\gamma_{x y}\right) & =n_{\min }+\frac{\gamma_{x y}-\gamma_{\mathrm{tv}, \mathrm{M}}}{\gamma_{\mathrm{tl}}-\gamma_{\mathrm{tv}, \mathrm{M}}}\left(n_{0}-n_{\min }\right) \\
& =n_{0}-\frac{\gamma_{x y}-\gamma_{\mathrm{tl}}}{\gamma_{\mathrm{tv}, \mathrm{M}}-\gamma_{\mathrm{tl}}}\left(n_{0}-n_{\min }\right)
\end{aligned}
$$

31.

32.

$$
\varepsilon_{x}=\frac{\Delta h}{h_{0}}=\frac{V_{\mathrm{p}, 0}-V_{\mathrm{p}, 1}\left(\gamma_{x y}\right)}{V_{\mathrm{S}}+V_{\mathrm{p}, 0}}=n_{0}-n_{1}\left(\gamma_{x y}\right)
$$

$$
s=\int_{x} \varepsilon_{x} \mathrm{~d} x
$$

Subsidence, tilting and angular displacements of the foundations can lead to unacceptable strains and stresses in the structure. The angular displacements were calculated according to Equation 34 by reference to the differential settlements to the corresponding horizontal distance. For the considered charge depths $d_{\mathrm{TNT}}$, the corresponding curves $\tan \beta=f\left(r_{\text {hor }}\right)$ are shown in Figure 28. The safe distance $r_{\text {horsafe }}$ is reached when the angular rotation falls below a limit value. According to DIN EN 1997-1, appendix H (DIN, 2009), the criterion for freedom of damage was assumed as $\tan \beta=1 / 500$.

34. $\tan \beta=\frac{\Delta s}{\Delta r_{\text {hor }}}$

\section{Results and discussion}

Figure 29 gives the safe horizontal distance $r_{\text {hor,safe }}$, beyond which a building remains undamaged. The three curves were derived in the previous sections. They correspond to the three damage patterns air blast, vibrational stimulation of the footing of the structure and inadmissible angular distortion of foundations due to subsidence. For a given charge depth $d_{\text {TNT }}$, one has to draw a vertical line. From the intersection of the vertical line with a curve, one has to draw a horizontal line to the ordinate on the left side of the diagram. Intersection of the horizontal line with the ordinate gives the safe horizontal distance that corresponds to the considered curve. Thus, for a given charge depth $d_{\mathrm{TNT}}$, the upmost of the three intersections is in general decisive and the upper part of the diagram that lies above all three curves designates safe distances. In the case of soil that is not prone to subsidence, the upmost intersection of the two curves that correspond to air blast (criterion number 1) and vibrational stimulation of the structure (criterion number 2 ) is relevant.

When comparing the air blast criterion with the criterion for vibrational stimulation of the structure, it is noticeable that the air blast criterion at low charge depth is decisive, while for larger charge depths, the vibrational excitation of the structure determines the safe distance. This is logical, as with increasing charge depth, the proportion of the explosive energy that is transferred into the soil and that propagates in the form of direct ground shock waves increases.

Since the sagging criterion is relevant only to subsidence-prone soils, it will be discussed separately. The smaller the charge depth $d_{\mathrm{TNT}}$, the greater is the safe distance for the sagging

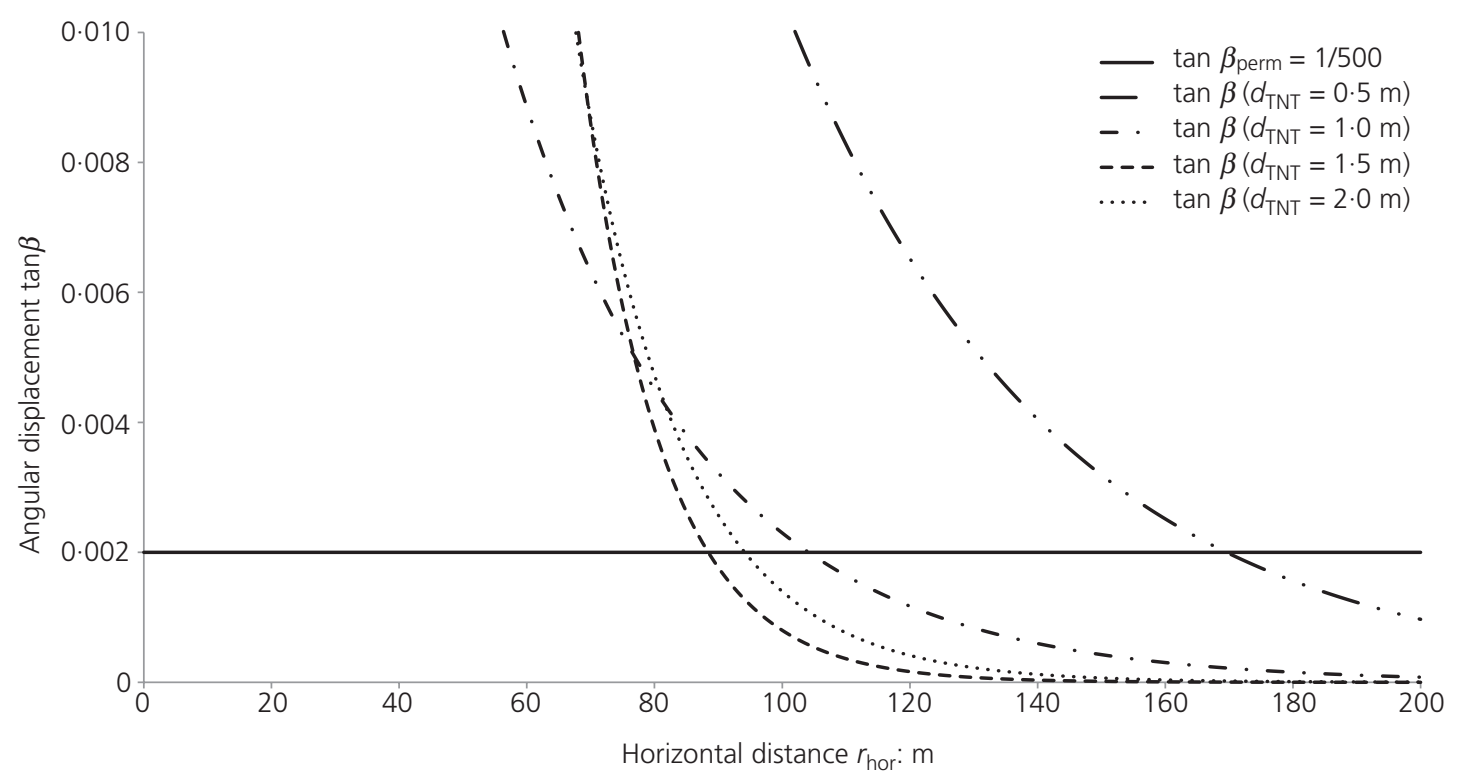

Figure 28. Sagging-induced angular displacement $\tan \beta=f\left(r_{\text {hor }}\right)$ for different charge depths $d_{\text {TNT }}$ 


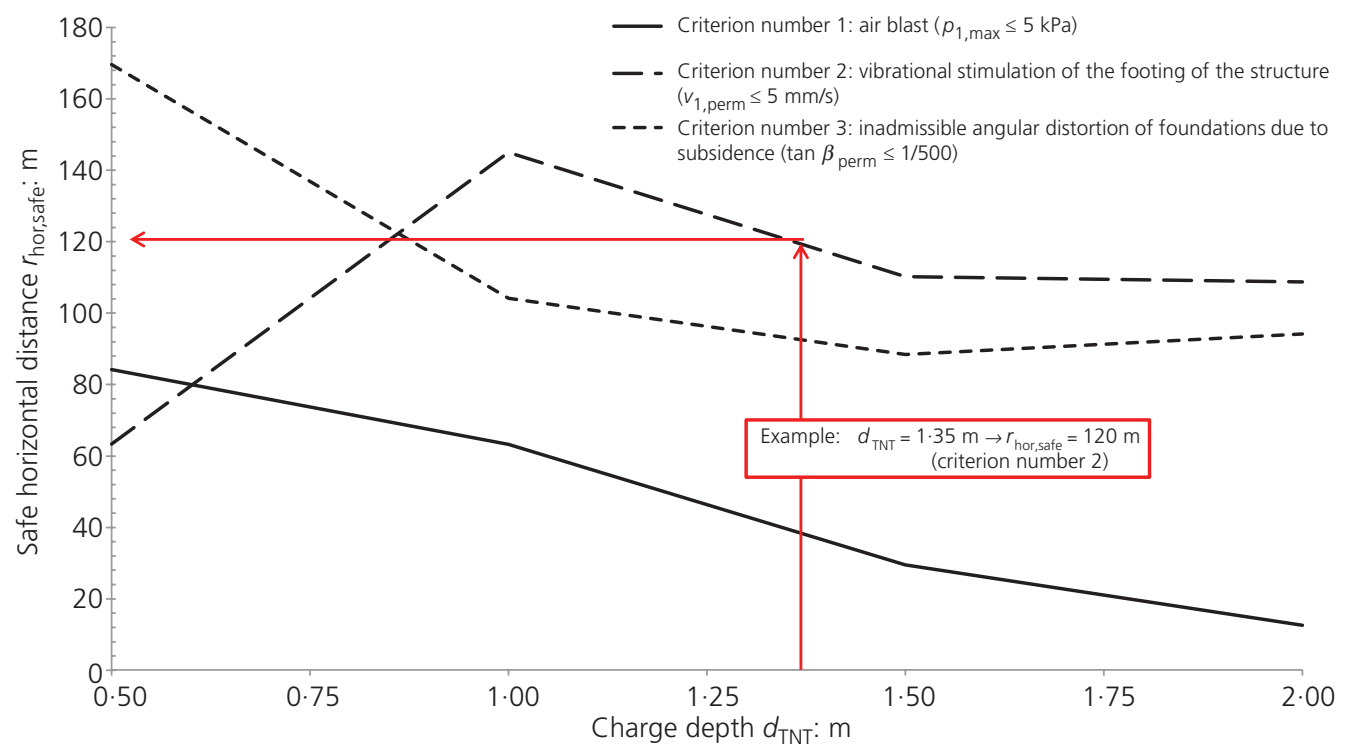

Figure 29. Safe horizontal distance $r_{\text {hor, safe }}$ for undamaged buildings

criterion in Figure 29. This may seem surprising at first, since for the shallowest charge depth $d_{\mathrm{TNT}}=0.5 \mathrm{~m}$, the least energy is transmitted to the soil and the direct ground shock wave should thus have a much shorter range. However, it seems that for the shallowest charge depth $d_{\mathrm{TNT}}=0.5 \mathrm{~m}$ - if compared to the other charge depths considered in this study - a greater part of the explosive energy propagates in the form of Rayleigh waves. These are surface waves that tend to decay much slower with increasing distance than compression waves and shear waves. Additionally, the effect fits in principle to the statement that airinduced, indirect ground shock waves have greater displacement and acceleration amplitudes than direct ground shock waves (Cook et al., 1962).

The diagram in Figure 29 applies to a charge mass of $W_{\mathrm{TNT}}=$ $125 \mathrm{~kg}$ and a dry, medium-dense sand as foundation soil. For other load masses and other ground conditions, separate charts must be created.

\section{Conclusion}

The aim of this study was to develop a procedure for the creation of a decision aid with which the impact of shock waves induced by underground, near-surface explosions on buildings can be estimated.

First, the theoretical basics of shock waves were explained. The influence of the relevant parameters - state of stress and strain, form of the compression curve and strain rate - was demonstrated.

Numerical simulations were conducted with the commercial hydrocode Autodyn. The aim was to determine the timings of the air pressure as well as the timings of the horizontal particle velocity and the shear strain (both in the subsoil). The mentioned parameters are respectively decisive for the three considered damage patterns air blast, vibrational stimulation of the footing of the structure and inadmissible angular distortion of foundations due to subsidence. To keep track of the blast wave over great distances, the modelling strategy of the moving window was developed. The simulations were performed with a charge mass of $125 \mathrm{~kg}$ of TNT at different charge depths between 0.5 and $2.0 \mathrm{~m}$ below ground level and for dry sand.

The safe distance $r_{\text {horsafe }}$ at which a building will remain undamaged in the event of a near-surface, underground explosion can be taken from Figure 29. The diagram thus allows a quick and easy answer to the question: how large must the minimal horizontal distance between a building and the epicentre of an explosion - characterised by the explosive, the charge mass and depth - be so that the building remains undamaged?

\section{Acknowledgements}

The material presented in this paper is based on the study 'Effects of Artificially Weapon-induced Earthquakes' supported by the German Federal Ministry of Defence. The authors are indebted to Dipl.-Ing. (FH) Heidi Noack for the initiation of this study and her continuing interest in further work on this topic.

\section{REFERENCES}

Anderson CE (1987) An overview on the theory of hydrocodes. International Journal of Impact Engineering 5(1-4): 33-59, http://dx.doi.org/10.1016/0734-743X(87)90029-7.

Ansys Inc. (2013) ANSYS Mechanical User's Guide - Release 15.0. Ansys Inc., Canonsburg, PA, USA. 
Bessette GC (2008) Modeling blast loading on buried reinforced concrete structures with Zapotec. Shock and Vibrations 15(2): 137-146, http://dx.doi.org/10.1155/2008/719215.

Century Dynamics Inc. (2005a) AUTODYN Theory ManualRevision 4.3. Century Dynamics Inc., Concord, CA, USA.

Century Dynamics Inc. (2005b) AUTODYN Remapping Tutorial Revision 4.3. Century Dynamics Inc., Concord, CA, USA.

Cook MA, Keyes RT and Ursenbach WO (1962) Air blast and ground shock waves generated at long distances from demolitions of high explosives. Journal of Applied Meteorology 1: 91-101, http://dx.doi.org/10.1175/1520-0450 (1962)001\%3C0091\%3AABAGSW\%3E2.0.CO\%3B2.

DIN (Deutsches Institut für Normung e.V.) (1999) DIN 4150-3: Erschütterungen im Bauwesen, Teil 3: Einwirkungen auf bauliche Anlagen. Beuth, Berlin, Germany (in German).

DIN (2009) DIN EN 1997-1: Eurocode 7: Entwurf, Berechnung und Bemessung in der Geotechnik - Teil 1: Allgemeine Regeln. Beuth, Berlin, Germany (in German).

Drake JL and Little CDJ (1983) Ground Shock from Penetrating Conventional Weapons. US Army Engineer Waterways Experiment Station, Vicksburg, MI, USA.

Drake JL, Smith EB and Blouin SE (1989) Enhancements of the prediction of ground shock from penetrating weapons. Proceedings of the 4th International Symposium on the Interaction of Non-nuclear Munitions with Structures, Panama City Beach, FL, USA.

Fišerová D (2006) Numerical Analyses of Buried Mine Explosions with Emphasis on Effect of Soil Properties on Loading. Cranfield Defence and Security, Shrivenham, UK.

Grujicic M, Pandurangan B and Cheeseman BA (2006) The effect of degree of saturation of sand on detonation phenomena associated with shallow-buried and ground-laid mines. Shock and Vibration 13(1): 1-21, http://dx.doi.org/10.1155/2006/ 652405 .

Heinze H (1987) Sprengtechnik - Anwendungsgebiete und Verfahren. Deutscher Verlag für Grundstoffindustrie, Leipzig Stuttgart, Germany (in German).

Hiermaier S (2008) Structures under Crash and Impact. Springer, New York, NY, USA.

Hsu CC and Vucetic M (2004) Volumetric threshold shear strain for cyclic settlement. Journal of Geotechnical and Geoenvironmental Engineering 130(1): 58-70, http://dx.doi. org/10.1061/(ASCE)1090-0241(2004)130:1(58).

Laine L (2001) Numerical simulations of ground shock attenuation layers for Swedish rescue centres and shelters. In Proceedings of the 4th Asia-Pacific Conference on Shock and Impact Loads on Structures (Lok TS, CI-Premier Conference Organisation and Doboku Gakkai Impact Problem Committee (eds)). CI-Premier Conference Organisation, Singapore, vol. 4, pp. 353-360.

Laine L (2012) Markstötvag. Myndigheten för smhällsskydd och beredskap, Karlstad, Sweden, Publ.-Nr. MSB344 (in Swedish).

Laine $L$ and Sandvik A (2001) Derivation of mechanical properties for sand. In Proceedings of the 4th Asia-Pacific Conference on
Shock and Impact Loads on Structures (Lok TS, CI-Premier Conference Organisation and Doboku Gakkai Impact Problem Committee (eds)). CI-Premier Conference Organisation, Singapore, vol. 4, pp. 361-368.

Lu Y and Wang Z (2006) Characterization of structural effects from above-ground explosion using coupled numerical simulation. Computers and Structures 84(28): 1729-1742, http://dx.doi.org/10.1016/j.compstruc.2006.05.002.

Lu Y, Hao H and Ma G (2002) Experimental investigation of structural response to generalized ground shock excitations. Experimental Mechanics 42(3): 261-271, http://dx.doi.org/10. 1007/BF02410981.

Lu Y, Wang Z and Chong K (2005) A comparative study of buried structure in soil subjected to blast loading using $2 \mathrm{D}$ and $3 \mathrm{D}$ numerical simulations. Soil Dynamics and Earthquake Engineering 25(4): 275-288, http://dx.doi.org/10.1016/j. soildyn.2005.02.007.

Meyers MA (1994) Dynamic Behavior of Materials. Wiley, New York, NY, USA.

Nato (North Atlantic Treaty Organization) (2010) Allied Ammunition Storage and Transport Publication 1 (AASTP-1): Manual of NATO Safety Principles for the Storage of Military Ammunition and Explosives. Defence Investment Division, North Atlantic Treaty Organization International Staff, Brussels, Belgium.

Omidvar M, Iskander M and Bless S (2012) Stress-strain behaviour of sand at high strain rates. International Journal of Impact Engineering 49: 192-213, http://dx.doi.org/10.1016/j. ijimpeng.2012.03.004.

Showichen A (2008) Numerical Analysis of Vehicle Bottom Structures Subjected to Anti-tank Mine Explosions. Cranfield Defence and Security, Shrivenham, UK.

Steidinger M and Krüning B (1991) Mustersicherheitsanalyse nach §7 Störfall V für eine Sprengstoffabrik. Bundesanstalt für Materialforschung und -prüfung (BAM), Berlin, Germany (in German).

Streitkräfteamt Abt V Infrastruktur (2007) Handbuch für die Grundlagen zur Bemessung von Bauwerken gegen die Wirkung konventioneller Waffen. Streitkräfteamt Abt V Infrastruktur, Bonn, Germany (in German).

Vucetic M (1994) Cyclic threshold shear strains in soils. Journal of Geotechnical Engineering 120(12): 2208-2228, http://dx. doi.org/10.1061/(ASCE)GT.1943-5606.0001461.

Wang Z, Lu Y, Hao H and Chong K (2005) A full coupled numerical analysis approach for buried structures subjected to subsurface blast. Computers and Structures 83(4-5): 339-356, http://dx.doi.org/10.1016/j.compstruc.2004.08.014.

Wilkins ML (1999) Computer Simulation of Dynamic Phenomena. Springer, Berlin, Germany.

Wu C and Hao H (2005) Modeling of simultaneous ground shock and airblast pressure on nearby structures from surface explosions. International Journal of Impact Engineering 31(6): 699-717, http://dx.doi.org/10.1016/j.ijimpeng.2004.03.002.

Wu C and Hao H (2007) Numerical simulation of structural response and damage to simultaneous ground shock and airblast loads. 
Geotechnical Research

Volume 3 Issue 3
Underground explosions: estimating the

safe distance

Zimbelmann and Boley
International Journal of Impact Engineering 34(3): 556-572, http://dx.doi.org/10.1016/j.ijimpeng.2005.11.003.

Zimbelmann JKR (2015) Beitrag zur Boden-Bauwerk-Interaktion in nichtbindigen Böden infolge hochdynamischer Anregung.
Dr.-Ing. thesis, University of the German Armed Forces. Munich, Germany (in German).

Zukas JA (2004) Introduction to Hydrocodes. Elsevier, Amsterdam, the Netherlands.

\section{HOW CAN YOU CONTRIBUTE?}

To discuss this paper, please submit up to 500 words to the editor at journals@ice.org.uk. Your contribution will be forwarded to the author(s) for a reply and, if considered appropriate by the editorial board, it will be published as a discussion in a future issue of the journal. 